\title{
A channel transmission losses model for different dryland rivers
}

\author{
A. C. Costa ${ }^{1}$, A. Bronstert ${ }^{1}$, and J. C. de Araújo ${ }^{2}$ \\ ${ }^{1}$ University of Potsdam, Institute of Earth and Environmental Sciences, Karl-Liebknecht-Str. 24/25, 14476 Potsdam, Germany \\ ${ }^{2}$ Federal University of Ceará, Department of Agricultural Engineering, Bloco 804 - Campus do Pici, \\ CEP 60 455-970, Fortaleza, CE, Brazil
}

Correspondence to: A. C. Costa (cunhacos@uni-potsdam.de)

Received: 8 September 2011 - Published in Hydrol. Earth Syst. Sci. Discuss.: 4 October 2011

Revised: 16 January 2012 - Accepted: 16 March 2012 - Published: 3 April 2012

\begin{abstract}
Channel transmission losses in drylands take place normally in extensive alluvial channels or streambeds underlain by fractured rocks. They can play an important role in streamflow rates, groundwater recharge, freshwater supply and channel-associated ecosystems. We aim to develop a process-oriented, semi-distributed channel transmission losses model, using process formulations which are suitable for data-scarce dryland environments and applicable to both hydraulically disconnected losing streams and hydraulically connected losing(/gaining) streams. This approach should be able to cover a large variation in climate and hydro-geologic controls, which are typically found in dryland regions of the Earth. Our model was first evaluated for a losing/gaining, hydraulically connected $30 \mathrm{~km}$ reach of the Middle Jaguaribe River (MJR), Ceará, Brazil, which drains a catchment area of $20000 \mathrm{~km}^{2}$. Secondly, we applied it to a small losing, hydraulically disconnected $1.5 \mathrm{~km}$ channel reach in the Walnut Gulch Experimental Watershed (WGEW), Arizona, USA. The model was able to predict reliably the streamflow volume and peak for both case studies without using any parameter calibration procedure. We have shown that the evaluation of the hypotheses on the dominant hydrological processes was fundamental for reducing structural model uncertainties and improving the streamflow prediction. For instance, in the case of the large river reach (MJR), it was shown that both lateral stream-aquifer water fluxes and groundwater flow in the underlying alluvium parallel to the river course are necessary to predict streamflow volume and channel transmission losses, the former process being more relevant than the latter. Regarding model uncertainty, it was shown that the approaches, which were applied for the unsaturated zone processes (highly nonlinear with elaborate numerical solutions), are much more sensitive
\end{abstract}

to parameter variability than those approaches which were used for the saturated zone (mathematically simple water budgeting in aquifer columns, including backwater effects). In case of the MJR-application, we have seen that structural uncertainties due to the limited knowledge of the subsurface saturated system interactions (i.e. groundwater coupling with channel water; possible groundwater flow parallel to the river) were more relevant than those related to the subsurface parameter variability. In case of the WEGW application we have seen that the non-linearity involved in the unsaturated flow processes in disconnected dryland river systems (controlled by the unsaturated zone) generally contain far more model uncertainties than do connected systems controlled by the saturated flow. Therefore, the degree of aridity of a dryland river may be an indicator of potential model uncertainty and subsequent attainable predictability of the system.

\section{Introduction}

Dryland rivers can be classified into (a) allogenic rivers, which are sourced almost entirely from upstream humid areas (e.g. the River Nile in Northern Sudan and Egypt) and commonly sustain perennial flow partly infiltrating in the alluvial system along the allogenic river, and (b) endogenic rivers, which are sourced almost entirely within dryland environments and usually show an ephemeral (non-baseflow) or intermittent flow (Bull and Kirkby, 2002). Channel transmission losses in drylands occur in both types of dryland rivers. They take place normally in extensive alluvial channels (Renard et al., 2008) or streambeds underlain by fractured rocks (Hughes, 2008). They can play an important role in streamflow rates, groundwater recharge, freshwater 
supply and channel-associated ecosystems (Goodrich et al., 2004; Blasch et al., 2004; Lange, 2005; Dagès et al., 2008; Wheater, 2008). The surface hydrological connectivity between dryland catchments and/or upstream and downstream reaches of dryland rivers occurs if and only if the runoff propagated into channels overcomes its transmission losses (based on Beven, 2002; Bracken and Croke, 2007). Consequently, runoff, sediment transport and channel morphology depend on how influential channel transmission losses are (Shannon et al., 2002).

When long time series of streamflow data are available, conceptual models and time series analysis may provide reliable prediction of channel transmission losses (Lane, 1983; Sharma and Murthy, 1994; Sharma et al., 1994; Hameed et al., 1996). However, monitoring of surface flow in dryland rivers is difficult in many regions, due to often low population density, the remoteness of hydrological stations and the inherent short duration of runoff (El-Hames and Richards, 1998). Moreover, extreme climatic variation from year to year, especially variation in annual precipitation, increases the problems of constructing probabilistic models (El-Hames and Richards, 1998). In this context, process-oriented hydrological models parameterized from field measurements and geo-database maps may be the most suitable or indeed the inevitable tool to predict both streamflow and channel transmission losses (e.g. El-Hames and Richards, 1998; Lange et al., 1999; Gheith and Sultan, 2002; Lange, 2005; Costelloe et al., 2006; Morin et al., 2009).

Channel transmission losses can occur in streams which are hydraulically connected or disconnected with a groundwater system (Sophocleous, 2002; Ivkovic, 2009). Streams which only recharge groundwater are called losing (or influent) streams while those which both recharge and discharge groundwater are called losing/gaining (or effluent) streams (Ivkovic, 2009). Discussion on the hydrological processes involved in channel transmission losses can be found, e.g. in Renard (1970), Abdulrazzak and Morel-Seytoux (1983), Knighton and Nanson (1994), Lange et al. (1998), Dunkerley and Brown (1999), Lange (2005), Konrad (2006), Dahan et al. $(2007,2008)$ and Dagés et al. (2008). From those studies, channel transmission losses may be seen to behave as follows: small sub-bank flows must firstly fill pool abstractions and channel filaments in order to propagate downstream; then bank-full flows infiltrate predominantly into bed and levees; and, at high stream discharges, overbank flows lose water for pools, subsidiary channels and floodplains, but once they become fully saturated, the most direct floodways become fully active and channel transmission losses decrease. However, this behaviour may vary depending on the seasonality, the underlying subsurface water flow and the (micro-)layered structure of alluvial and floodplain sediments.

If the groundwater level is too deep, i.e. below the level of the river bed, seepage flow may be predominantly vertical and unsaturated. In contrast, if there is shallow groundwater present, seepage may be primarily lateral and saturated, effecting the development of a groundwater mound. Depending on the interaction between stream and groundwater and the variations of the groundwater level, the seepage may even shift from being vertical and unsaturated to being lateral and saturated in the same dryland stream-groundwater system. However, independently of the underlying groundwater, not every flood will result in deep infiltration and, consequently, groundwater recharge, because of lateral subsurface flow dispersion through the layered structure of alluvial sediments (Renard, 1970; Dahan et al., 2007). On the other hand, rapid deep infiltration may be driven by an active preferential flow mechanism that bypasses the porous matrix of the vadose zone (Dahan et al., 2007). Moreover, stream-aquifer exchanges may constitute hyporheic flow as in the case where a stream loses flow to a shallow aquifer that discharges back to the stream in a downstream reach due to decrease in aquifer thickness, aquifer narrowing and/or decrease in aquifer hydraulic conductivity (Konrad, 2006). In this way, the groundwater table rises due to the upstream groundwater recharge (Dahan et al., 2007).

Hydrological modelling of channel transmission losses for hydraulically (dis)connected losing/gaining streams has been based on the concept of leakage coefficient (Rushton and Tomlinson, 1979), which has been used to model the water fluxes between stream and (shallow) groundwater flows (see e.g. applications in Krause and Bronstert, 2007; Xie and Yuan, 2010; Engeler et al., 2011). This approach has been successfully applied to catchments and river reaches, especially in temperate and humid regions, linking distributed river and groundwater flow models. However, the leakage coefficient concept fails to model disconnected losing streams, because it neglects unsaturated flow through the alluvium (Brunner et al., 2010).

Hydraulically connected losing streams can also be modelled using the Green-and-Ampt infiltration approach (Abdulrazzak and Morel-Seytoux, 1983). However, the Greenand-Ampt infiltration approach turns on an equation without analytical solution for disconnected streams, because in-channel ponding depth and gravitational terms are timedependent (Freyberg et al., 1980). To overcome this difficulty, Freyberg (1983) proposed a numerical solution (trapezoidal quadrature) of the Green-and-Ampt equation for a uniform alluvium. His algorithm was initiated by the analytic solution to a non-gravity approximation due to the singularity in infiltration rate at time equal to zero and the inadequacy of the trapezoidal quadrature for rapid change in infiltration rate at small time steps (Freyberg, 1983). Therefore, unsaturated flow through the alluvium, together with in-channel variable ponding depth, hampers a transmission losses model for disconnected losing streams. An extra difficulty might be the existence of an underlying stratified alluvium, which can often be found in dryland riverscapes (Parissopoulos and Wheater, 1992; El-Hames and Richards, 1998). 
Another approach for disconnected losing streams is the Smith-Parlange infiltration equation used in KINEROS2 model, which is based on an approximate solution of the basic equation of unsaturated flow (Smith et al., 1995; Semmens et al., 2008). The model requires basically three parameters (the integral capillary drive, the field effective saturated hydraulic conductivity and soil water content) to describe the infiltration behaviour, but the underlying soil profile can only be represented by two-layers, with each layer allowed to have different infiltration parameters (Smith et al., 1995; Semmens et al., 2008).

Pressure-head-based Richards' equation enables us to model unsaturated flow through the alluvium considering both in-channel variable ponding depth and stratified alluvium as done by El-hames and Richards (1998). This might be the most physically comprehensive approach to model channel transmission losses for disconnected losing streams. However, its application can require a long processing time to simulate large- and meso-scale catchments (El-hames and Richards, 1998) and large sets of alluvium data, which are usually not available, especially in dryland environments. Alternatively, some authors have used constant infiltration rates in the channels (Lange et al., 1999; Morin et al., 2009), neglecting both in-channel variable ponding depth and unsaturated flow.

In this paper, we present a process-oriented and semidistributed channel transmission losses model using process formulations which are suitable for data-scarce dryland environments, applicable for both hydraulically disconnected losing streams and hydraulically connected losing(/gaining) streams in dryland environments, considering a possible transition between the two states. Hence, this approach should be able to cover a large variation in climate and hydro-geologic controls, which are typically found in dryland regions of the Earth. We expect this new model to be able to predict the order of magnitude of the hydrograph volume and peak, both variables being relevant for water planning and management in arid and semi-arid environments. However, note that we do not focus specifically on the prediction of the timing of the hydrograph peak, i.e. this model is not aiming at flood forecasting in dryland regions.

Our channel transmission losses model is first evaluated for an intermittent $30 \mathrm{~km}$ reach of the Middle Jaguaribe River (MJR), Ceará, Brazil, which drains a catchment area of $20000 \mathrm{~km}^{2}$. Secondly, we apply it to an ephemeral small $1.5 \mathrm{~km}$ channel reach in the Walnut Gulch Experimental Watershed (WGEW), Arizona, USA, which is well-known for its long-term database of semi-arid hydrology and studies on channel transmission losses (e.g. Renard, 1970; Renard et al., 2008; Stone et al., 2008). The MJR is a losing/gaining (mostly losing) river and hydraulically connected to the groundwater system; the small reach in the WGEW on the other hand is a losing stream and hydraulically disconnected to the groundwater system.
The application of the model to these channel reaches will be undertaken in order to evaluate the model capabilities in two rather different dryland environments. Also, we will test hypotheses on the dominant hydrological processes with a view to generating insights into process functioning through comparisons of model performance (Savenije, 2009; Graeff et al., 2009; Li et al., 2010; Buytaert and Beven, 2011; McMillan et al., 2011; Clark et al., 2011).

Although increasing efforts have been made in the acquisition of remote sensing data, which have been used to derive, e.g. precipitation data, soil moisture data, digital elevation models (DEMs), land-cover maps and river networks (see e.g. Milewski et al., 2009), the applicability of processoriented, distributed hydrological models to arid and semiarid catchments is still only feasible in exceptional cases due to generally sparse data, and high spatial variability, of surface and subsurface systems (see e.g. Al-Qurashi et al., 2008). Therefore, we want to analyse the applicability and predictive capability of our model by both individual parameter sensitivity analysis and an overall model parameter uncertainty analysis.

\section{Modelling of channel transmission losses}

Conceptually, we consider the following processes, which have been shown experimentally to be the most influential for channel transmission losses (see discussion in introduction):

1. streamflow in natural rivers;

2. unsaturated seepage under in-channel variable ponding depth through a stratified alluvium;

3. vertical unsaturated subsurface water redistribution beneath the stream;

4. lateral (stream-)aquifer interaction, which includes the development of a groundwater mound and;

5. groundwater flow, parallel to the river course, in unconfined aquifers.

We establish possible in/outflow through the different boundaries of the modelled system, such as surface and subsurface inflow from the landscape adjacent to the river corridor, evapotranspiration from the streambed and groundwater extraction by root water uptake. These fluxes might be external hydrological process models or prescribed as scenarios. The model structure is composed of five spatial components, which we consider to represent an appropriate spatial model scale for the governing processes and which enables a spatial coupling of the sub-models of the processes, see Fig. 1 for a schematic overview.

The whole channel transmission losses model includes six interacting sub-models for the aforementioned governing processes, which are presented in detail in Sects. 2.1 to 2.5, and schematicised in Fig. 2. 


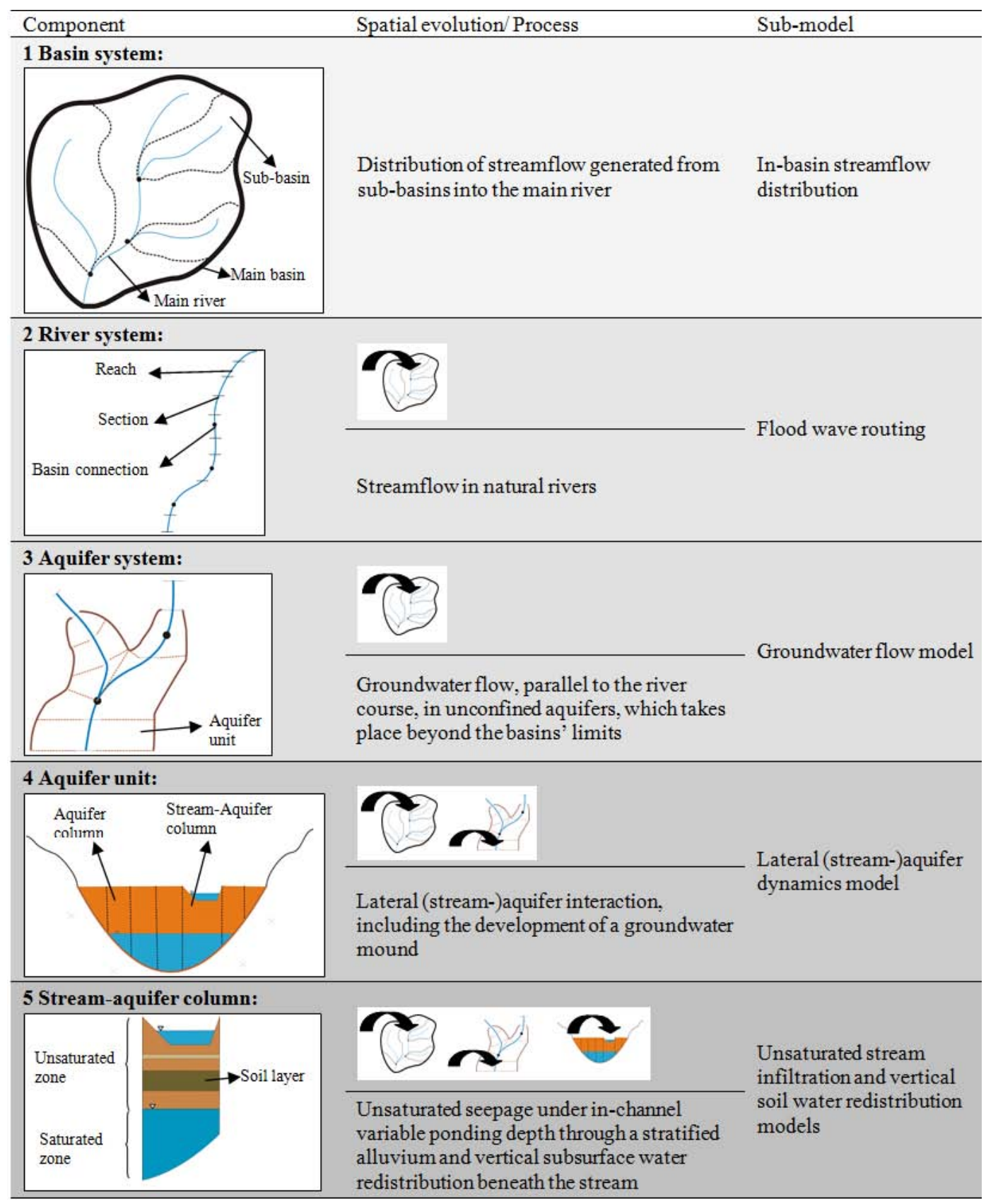

Fig. 1. Spatial components of the model structure, which link the sub-models of the governing processes involved in channel transmission losses.

The calculation begins with the flood wave routing without stream-aquifer interaction, i.e. we predict firstly streamflow and stream water stage excluding stream-aquifer interaction fluxes. Then, we use these predicted "intermediate" values of streamflow and water stage to run the other sub-models (2, 3, 4 and 5), which estimate (a) the streamaquifer interaction flux and (b) the moisture in the underlying aquifer. Afterwards, we apply the streamflow routing again, but now with the estimated stream-aquifer interaction flux, to predict finally the streamflow and water stage at the end of the time step. This kind of solution of streamflow and water stage is a two-step procedure, which was discussed e.g. by Mudd (2006) and Bronstert et al. (2005).

As long as the stream-aquifer column is not saturated, the stream and groundwater flows are hydraulically disconnected, while channel transmission losses are dominated by the unsaturated zone beneath the stream. Once the stream-aquifer column has been saturated, the stream and 


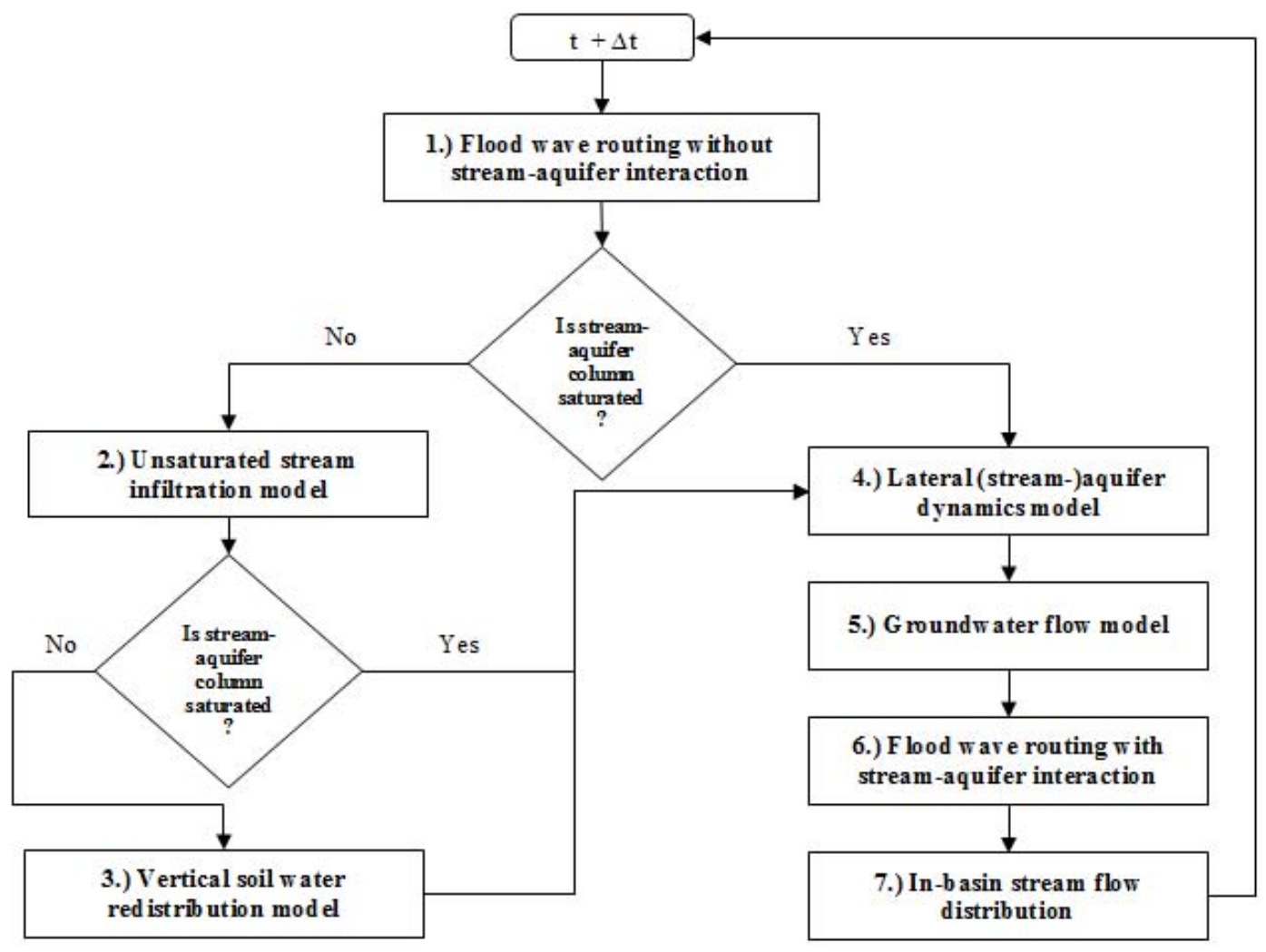

Fig. 2. Interplay and temporal sequence of model approaches, where $t$ is time.

groundwater turn into a hydraulically connected system, wherein channel transmission losses are driven by the saturated zone, which either can discharge to or recharge from the stream.

The following Sects. 2.1 to 2.5 describe the physical assumptions and the main mathematical formulations for the sub-models of our channel transmission losses model. We detail the stream-aquifer interaction calculation in Sect. 2.6. Finally, we summarize the information required to run the model (both input data and model parameters) in Sect. 2.7.

\subsection{Flood wave routing}

Normally the full Saint-Venant equations and its simplified diffusion analogy form are applied to simulate streamflow in a natural drainage network, when the up- and downstream boundary conditions are available. However, most dryland streams have no "fixed" downstream boundary conditions because many hydrographs end somewhere between initial streamflow and an assumed outlet, which is normally ungauged. Moreover, sparse monitoring can mean that entire drainage network from the initial streamflow is completely ungauged. Furthermore, simple routing approaches such as the Muskingum-method and the Manning-formula may yield poor approximation of the river dynamics when both inertial and pressure forces are important, such as in mild-sloped rivers, and backwater effects from downstream disturbances are not negligible (see Chow et al., 1988). Therefore, we propose here an alternative flood wave routing.

First, we use a form of conservation of mass equation

$\frac{\partial Q}{\partial x}+s \frac{\partial A}{\partial t}=q+I_{\mathrm{RA}}$

where $t$ is the time (T), $x$ is the length along the channel axis (L), $Q$ is the stream discharge $\left(\mathrm{L}^{3} \mathrm{~T}^{-1}\right), A$ is the wetted cross-sectional area $\left(\mathrm{L}^{2}\right), s$ is the sinuosity coefficient (dimensionless), $q$ is the lateral inflow per unit of length of channel $\left(\mathrm{L}^{3} \mathrm{~T}^{-1} \mathrm{~L}^{-1}\right)$ and $I_{\mathrm{RA}}$ is the stream-aquifer interaction term per unit of length of channel $\left(\mathrm{L}^{3} \mathrm{~T}^{-1} \mathrm{~L}^{-1}\right)$, which can be stream infiltration (negative) or groundwater discharge (positive).

Applying the four-implicit numerical scheme (see Fread, 1993) to Eq. (1), yields

$$
\begin{aligned}
& Q_{i+1}^{j+1}=Q_{i}^{j+1}-\frac{\left(1-\theta_{\Delta x}\right)}{\theta_{\Delta x}}\left(Q_{i+1}^{j}-Q_{i}^{j}\right) \\
& +\frac{\Delta x_{i}}{\theta_{\Delta x}}\left[\bar{q}+I_{\mathrm{RA}}-s \frac{\left(A_{i+1}^{j+1}+A_{i}^{j+1}-A_{i+1}^{j}-A_{i}^{j}\right)}{2 . \Delta t_{j}}\right]
\end{aligned}
$$

where $j$ and $i$ are indexes of time and stream section, respectively, and $\theta_{\Delta x}$ is a weighting factor for the spatial derivative. Equation (2) has two unknown variables: the stream 
discharge and the wetted cross-sectional area (related to the stream water stage) at the future time and at the next stream section: $Q(j+1, i+1)$ and $A(j+1, i+1)$, respectively.

Since, in natural streams, the channel morphology is a function of both the short and the long term stream hydrology, the channel cross-section is a function of the past and upstream flood events. It means that all the information (e.g. change in the velocity, in the water depth and in the bed slope) for the future and further stream discharge $Q(j+1, i+1)$ is already "imprinted on" the wetted crosssectional area $A(j+1, i+1)$. Taking this hypothesis into account, we get all the states for $A(j+1, i+1)$ and substitute into Eq. (2) to find possible states for $Q(j+1, i+1)$ according to the conservation of mass equation. Then, we average over the possible states of $Q(j+1, i+1)$ and $A(j+1, i+1)$, which obey the following simple physical rules:

$$
\left\{\begin{array}{l}
Q_{i+1}^{j+1} \geq 0 \\
\text { if } Q_{i}^{j+1}<Q_{i+1}^{j+1}, \text { then } A_{i}^{j+1}<A_{i+1}^{j+1} \\
\text { if } Q_{i}^{j+1}>Q_{i+1}^{j+1} \text {, then } A_{i}^{j+1}>A_{i+1}^{j+1} \\
\text { if } Q_{i+1}^{j+1} \neq 0, \text { then } A_{i+1}^{j+1} \neq 0 \\
\text { if } Q_{i+1}^{j+1}=0, \text { then } A_{i+1}^{j+1}=0
\end{array}\right.
$$

Equation (3) can be seen as a physical filter of the states for $Q(j+1, i+1)$ and $A(j+1, i+1)$. It can be applied for both stream stretches in sub-basins and for the main river stretch, see Fig. 1. If the next stream section is the last section in a sub-basin, the calculated stream discharge at this section, i.e. the catchment runoff from the sub-basin, is added as lateral inflow into the reach of the main river stretch.

The Courant-Friedrichs-Lewy (CFL) condition may be used as a condition for numerical stability

$\Delta t_{\text {sim }} \leq \frac{\Delta x_{\min }}{v_{\max }}$

where $v_{\max }$ is the maximum expected stream velocity $\left(\mathrm{L} \mathrm{T}^{-1}\right), \Delta x_{\min }$ is the minimum stream reach and $\Delta t_{\mathrm{sim}}$ is the time step (T) for simulation.

This simplified formulation for flood-wave dynamics in dryland rivers is, however, able to mimic loop rating curves and backwater effects, which have been observed during the unsteady, non-uniform flow propagation along natural streams. We expect that hydrograph uncertainties (e.g. timing of the hydrograph) will inevitably arise because of the very high dependence of flow velocity on the actual channel cross-sections and roughnesses, whose data may be highly variable with time (affected by the seasonality of riverine vegetation or by previous flood events); such data may be rarely available and whose seasonal and long-term changes between different simulation periods might not be measured.

\subsection{Unsaturated stream infiltration}

We adapt here the modified Green-and-Ampt model proposed by Chu and Mariño (2005), because we consider it a suitable compromise between computation time, data requirement and simplifying assumptions (e.g. constant infiltration rates). The alluvium beneath the stream (Fig. 1) consists of $N$ layers with hydraulic conductivities $K_{N}\left(\mathrm{~L} \mathrm{~T}^{-1}\right)$, wetting-front suctions $\psi_{N}(\mathrm{~L})$, porosities $\eta_{N}\left(\mathrm{~L}^{3} \mathrm{~L}^{-3}\right)$, initial soil moisture $\theta_{N}\left(\mathrm{~L}^{3} \mathrm{~L}^{-3}\right)$ and depths of cumulative infiltration $z_{N}(\mathrm{~L})$. When the wetting front is in a layer $y$ at location $z\left(Z_{y-1}<z \leq Z_{y}\right)$, the governing equations are

$$
\begin{aligned}
f_{z} & =\frac{H_{0}+z+\psi_{y}}{\sum_{k=1}^{y-1} \frac{Z_{k}-Z_{k-1}}{K_{k}}+\frac{z-Z_{y-1}}{K_{y}}} \\
F_{z}= & F_{z y-1}+\left(z-Z_{y-1}\right)\left(\eta_{y}-\theta_{y}\right) \\
= & \sum_{k=1}^{y-1}\left(Z_{k}-Z_{k-1}\right)\left(\eta_{k}-\theta_{k}\right)+\left(z-Z_{y-1}\right)\left(\eta_{y}-\theta_{y}\right) \\
f_{z} & =\frac{\mathrm{d} F_{z}}{\mathrm{~d} t}=\left(\eta_{y}-\theta_{y}\right) \frac{\mathrm{d} z}{\mathrm{~d} t}
\end{aligned}
$$

where $\mathrm{f}$ is the infiltration rate $\left(\mathrm{L} \mathrm{T}^{-1}\right), F$ is the cumulative infiltration (L), $t$ is the time for the wetting front to arrive at location $z$ and $H_{0}$ is the hydraulic head at surface (L), which was admittedly negligible in Chu and Mariño's formulation because their focus was on hillslope hydrology. Substituting Eq. (5) into Eq. (7) yields:

$$
\frac{H_{0}+z+\psi_{y}}{\sum_{k=1}^{y-1} \frac{Z_{k}-Z_{k-1}}{K_{k}}+\frac{z-Z_{y-1}}{K_{y}}}=\left(\eta_{y}-\theta_{y}\right) \frac{\mathrm{d} z}{\mathrm{~d} t} .
$$

Separating Eq. (8), since the hydraulic head at the surface is constant at a certain time step, we have:

$$
\int_{t_{z y-1}}^{t_{z}} \mathrm{~d} t^{\prime}=\int_{z_{y-1}}^{z} \frac{\left(\eta_{y}-\theta_{y}\right)\left(\sum_{k=1}^{y-1} \frac{Z_{k}-Z_{k-1}}{K_{k}}+\frac{z^{\prime}-Z_{y-1}}{K_{y}}\right)}{H_{0}+z^{\prime}+\psi_{y}} \mathrm{~d} z^{\prime} .
$$

Solving Eq. (9):

$$
\begin{aligned}
t_{z}= & t_{z y-1}+\frac{\left(\eta_{y}-\theta_{y}\right)\left(z-Z_{y-1}\right)}{K_{y}}+\left(\eta_{y}-\theta_{y}\right) \\
& {\left[\sum_{k=1}^{y-1} Z_{k}\left(\frac{1}{K_{k}}-\frac{1}{K_{k+1}}\right)-\frac{\psi_{y}+H_{0}}{K_{y}}\right] } \\
& \ln \left(\frac{z+\psi_{y}+H_{0}}{Z_{y-1}+\psi_{y}+H_{0}}\right)
\end{aligned}
$$

which is similar to the equation of the travel time of the wetting front from Chu and Mariño (2005), but with the hydraulic head at surface $H_{0}$. We use Eqs. (5) and (10) to estimate the actual infiltration and the location of the wetting front $z$. 
Before applying the above procedure to the next time step, when we have a new hydraulic head at the surface, the initial soil moisture has to be updated according to the location $z$ $\left(Z_{y-1}<z \leq Z_{y}\right)$ of the wetting front using:

$$
\theta_{y}^{j+1}=\left\{\begin{array}{l}
\eta_{y}, \text { for } z \leq Z_{y-1} \\
\frac{\eta_{y}\left(z-Z_{y-1}\right)+\theta_{y}^{j}\left(Z_{y}-z\right)}{Z_{y}-Z_{y-1}}, \text { for } Z_{y-1}<z \leq Z_{y} . \\
\theta_{y}^{j}, \text { for } z>Z_{y}
\end{array}\right.
$$

In this model, the hydraulic head at the surface (the upper boundary condition) is the average "intermediate" predicted values of stream water stage obtained from the solution of the flood wave routing (Sect. 2.1). The lower boundary condition is a layer, which can either represent fractured bedrocks (time independent) or be the soil layer immediately above the groundwater level (time dependent).

Once the wetting-front achieves the lowest layer, a hydraulically connected stream-lowest layer should now be considered and a groundwater mound is to be developed (Sect. 2.4). In contrast, the wetting-front flows vertically downward to the lowest layer (Sect. 2.3). For the first case, the infiltration rate tends to be constant and the capillary head zero as in Chu and Mariño (2005). Equation (5) can be rewritten as

$$
f_{z_{N}}=\frac{H_{0}+Z_{N}}{\sum_{k=1}^{N} \frac{Z_{k}-Z_{k-1}}{K_{k}}}
$$

where $Z_{N}$ is the depth of the considered alluvium profile above the groundwater level and $f_{Z_{N}}$ is the infiltration rate for a hydraulically connected surface-boundary condition system. The infiltration rate from unsaturated to saturated regime can be formulated as

$f_{\text {unsat-sat }}=\frac{t_{z} f_{z}}{\Delta t}+\frac{\left(\Delta t-t_{z}\right) f_{z_{N}}}{\Delta t}$

where $\Delta t$ is the time step. Note that the second element of the right term of Eq. (13) represents the first recharge to groundwater, if it exists, before the development of a groundwater mound.

\subsection{Vertical soil water redistribution}

In most unsaturated zone studies, the fluid motion is assumed to obey the classical Richards' equation (Hillel, 1980) and its 1-D soil moisture-based form is shown in the first two terms of Eq. (14), which is applicable in homogeneous media only and requires soil head-conductivity-moisture curves. We use here a simplification of the classical equation, which allows application in unsaturated heterogeneous media and needs less fitting parameters than the original form. First, we neglect the pressure head term $\psi(\theta)$ in Eq. (14), but we assume that percolation from one soil layer to the next layer below occurs if and only if the actual soil moisture exceeds soil moisture at field capacity $\theta_{\mathrm{fc}}$. This assumption was also used in other hydrological models (e.g. Arnold and Williams, 1995; Güntner and Bronstert, 2004), leading to

$$
\frac{\partial \theta}{\partial t}=\frac{\partial}{\partial z} K(\theta) \frac{\partial[\psi(\theta)+z]}{\partial z} \approx \frac{\partial}{\partial z} K(\theta) .
$$

We include in Eq. (14) the actual soil evaporation Eva for the upper soil layers and the actual evapotranspiration Eta for the soil layers in the root zone, in the case of existence of inchannel associated or riparian vegetation, which may be important for eco-hydrological studies and may allow insights into the relationship between channel transmission losses, inalluvium temporal water storage and ecological water demand. Furthermore we apply an explicit finite difference scheme to it

$$
\frac{\theta_{k}^{j+1}-\theta_{k}^{j}}{\Delta t}=\underbrace{\frac{K_{k-(1 / 2)}^{j}-K_{k+(1 / 2)}^{j}}{\Delta z}}_{\text {Percolation }}-\frac{\overbrace{\operatorname{Eta}_{k}^{j+1, j}+\operatorname{Eva}_{k}^{j+1, j}}^{\text {Transpiration }}}{\Delta z}
$$

where $k$ and $j$ are indexes of depth and time, respectively. The percolation terms of Eq. (15) are solved as follows

$$
\begin{aligned}
& K_{k+(1 / 2)}^{j}=\left\{\begin{array}{l}
\text { in - layer drainable } \\
\text { water } \\
\min \left(\frac{\Delta z\left(\theta_{k}^{j}-\theta_{\mathrm{fc}, k}\right)}{\Delta t} ; \sqrt{K_{k}\left(\theta_{k}^{j}\right) \cdot K_{k+1}\left(\theta_{k+1}^{j}\right)}\right), \text { for } \theta_{k}^{j}>\theta_{\mathrm{fc}, k} \\
0, \text { for } \theta_{k}^{j} \leq \theta_{\mathrm{fc}, k}
\end{array}\right. \\
& K_{k-(1 / 2)}^{j}=K_{(k-1)+(1 / 2)}^{j}
\end{aligned}
$$

where $K(\theta)$ is the unsaturated hydraulic conductivity, which is approached by the Brooks-and-Corey equation (see Rawls et al., 1993)

$K(\theta)=K_{\text {sat }}\left(\frac{\theta-\theta_{\mathrm{r}}}{\eta-\theta_{\mathrm{r}}}\right)^{3+\frac{2}{\lambda}}$

where $K_{\text {sat }}$ is the saturated hydraulic conductivity $\left(\mathrm{L} \mathrm{T}^{-1}\right), \theta_{\mathrm{r}}$ is the residual water content $\left(\mathrm{L}^{3} \mathrm{~L}^{-3}\right)$ and $\lambda$ is the pore size distribution index (-).

Note that if the lower layer $(k+1)$ is groundwater, there is a recharge to groundwater before the development of a groundwater mound because of the vertical movement of the soil water.

A separate hydrological catchment model can provide the potential soil evaporation and the potential evapotranspiration. Then, we assumed that evapotranspiration and soil evaporation occur if and only if the actual soil moisture exceeds soil moisture at permanent wilting point $\theta_{\text {pwp }}$ and at hygroscopic water $\theta_{\text {ha }}$, respectively. The computation begins with percolation, followed by an updating of $\theta_{k}^{j}$ and then the transpiration calculation. 


\subsection{Lateral (stream-)aquifer dynamics}

We consider that each aquifer unit is formed by $M$ columns, which may consist of saturated and unsaturated zones (Fig. 1). All these columns can be stratified such as that below the stream (Sects. 2.2 and 2.3). The lateral flow between the columns is considered saturated; consequently, we do not account for lateral unsaturated flow. Our aim is to predict in-column groundwater level (stream and groundwater levels for stream-aquifer columns), comparing the hydraulic heads between two column neighbours. During a time step, the calculation begins from the centre of the stream-aquifer column to the right (or the left) lateral boundary conditions (Fig. 1).

First, we calculate the hydraulic head of two column neighbours at the equilibrium $\left(h_{\mathrm{e}}\right)$, i.e.

$h_{\mathrm{e}}(A, A+1)=\frac{\mathrm{Cw}_{A} h_{A}+\mathrm{Cw}_{A+1} h_{A+1}}{\mathrm{Cw}_{A}+\mathrm{Cw}_{A+1}}$

where $A$ is the column index $(-), h$ is the in-column hydraulic head (L) and $\mathrm{Cw}$ is the column width (L). Then, assuming a subsurface water flow velocity similar to the order of magnitude of the lateral saturated hydraulic conductivity, we estimate the necessary time $\left(\mathrm{d} t_{\mathrm{e}}\right)$ to reach that equilibrium head using

$\mathrm{d} t_{\mathrm{e}}=\frac{\left|h_{\mathrm{e}}(A, A+1)-h_{A+1}\right|}{\bar{K}_{A+1}}$

where $\bar{K}_{A+1}$ is an average lateral saturated hydraulic conductivity from the actual head to the equilibrium ones $\left(\mathrm{L} \mathrm{T}^{-1}\right)$. If $\mathrm{d} t_{\mathrm{e}}$ is equal to or smaller than the simulation time step $\Delta t_{\text {sim }}$, then the heads of the column neighbours reach the equilibrium head, otherwise

$h_{A+1}^{*}=h_{A+1}+\frac{\Delta t_{\text {sim }}}{\mathrm{d} t_{\mathrm{e}}}\left[h_{\mathrm{e}}(A, A+1)-h_{A+1}\right]$

where $h_{A+1}^{*}$ is the new hydraulic head of column $A+1$ due to the exchanges with the column $A$. Afterwards, the column $A+1$ with the new hydraulic head $h_{A+1}^{*}$ will interact with its next neighbour $A+2$.

\subsection{Groundwater flow parallel to the river}

We use a simple water balance-based approach (similar to Niu et al., 2007) in order to simulate groundwater flow between aquifer units parallel to the river course (see Fig. 1)

$$
\begin{aligned}
\frac{\partial S_{\mathrm{GW}}}{\partial t} & =\overbrace{\left(Q_{\mathrm{Up}, \mathrm{GW}}+Q_{\mathrm{V}, \mathrm{Inf}}+Q_{\mathrm{La}, \mathrm{GW}}\right)}^{\text {Inflow }} \\
& -\underbrace{\left(Q_{\mathrm{Do}, \mathrm{GW}}+Q_{\mathrm{S}}+Q_{\mathrm{V}, \mathrm{DP}}\right)}_{\text {Outflow }}
\end{aligned}
$$

where $S$ is the groundwater storage in the aquifer unit $\left(\mathrm{L}^{3}\right)$, $Q_{\mathrm{Up}, \mathrm{GW}}$ and $Q_{\mathrm{La}, \mathrm{GW}}$ are the upstream and the lateral groundwater flow from other aquifer units $\left(\mathrm{L}^{3} \mathrm{~T}^{-1}\right)$, respectively, which are known from a previous time, $Q_{\mathrm{V}, \text { Inf }}$ is the vertical channel transmission losses $\left(\mathrm{L}^{3} \mathrm{~T}^{-1}\right)$, which come from unsaturated seepage (Sect. 2.2) or unsaturated soil water redistribution (Sect. 2.3), $Q_{\mathrm{Do}, \mathrm{GW}}$ is the downstream groundwater flow $\left(\mathrm{L}^{3} \mathrm{~T}^{-1}\right), Q_{\mathrm{S}}$ is a sink term $\left(\mathrm{L}^{3} \mathrm{~T}^{-1}\right)$, which can be groundwater pumping and/or transpiration, and $Q_{\mathrm{V}, \mathrm{DP}}$ is the vertical deep percolation $\left(\mathrm{L}^{3} \mathrm{~T}^{-1}\right)$, which is considered a constant (in)outflow. The downstream groundwater flow between aquifer units is estimated as follows

$$
\begin{aligned}
Q_{\mathrm{Do}, \mathrm{GW}}= & \frac{\overbrace{\min \left(\left|\bar{h}_{u+1}-\bar{h}_{u}\right| / \bar{K}_{u} ; \Delta t_{\mathrm{sim}}\right)}^{\text {Time Factor }}}{\Delta t_{\mathrm{sim}}} \\
& \cdot \bar{K}_{u} \frac{\bar{h}_{u+1}-\bar{h}_{u}}{\mathrm{~d} x_{u} / 2} \cdot \bar{h}_{u} \cdot W_{u}
\end{aligned}
$$

where $u$ is an index of aquifer unit, $\bar{h}$ is the average groundwater head of the aquifer unit $(\mathrm{L}), W$ is the aquifer unit width (L), $\mathrm{d} x_{u}$ is the aquifer unit length (L), $\bar{K}$ is the average aquifer unit saturated hydraulic conductivity $\left(\mathrm{L} \mathrm{T}^{-1}\right)$. Note that the downstream groundwater flow is compensated by a time factor, which is adopted similarly as was done in the previous section. The upstream boundary conditions are a constant flux. The user can define the downstream boundary conditions (a) as no-flow or (b) assuming that the gradient of the farthest downstream aquifer unit is equal to its closest upstream one.

After the estimation of aquifer water balance components, the difference between aquifer inflow and outflow is distributed for each column of the aquifer unit as follows

$Q_{\text {in(out) }, A}=\frac{\frac{\partial S_{\mathrm{GW}}}{\partial t} \cdot \mathrm{Cw}_{A}}{W_{U}}$

where $Q_{\text {in(out),A }}$ is the in-column inflow or outflow from the aquifer water balance $\left(\mathrm{L}^{3} \mathrm{~T}^{-1}\right)$. If $Q_{\mathrm{in}(\mathrm{out}), A}$ is inflow, than the updating of in-column groundwater level due to the aquifer water balance is modelled by

$Q_{\text {in(out }), A}=\frac{\sum_{c<k \leq b-1}\left(Z_{k+1}-Z_{k}\right)\left(\eta_{k+1}-\theta_{k+1}\right)}{\Delta t_{\text {sim }}}$

where $Z$ is the depth $(\mathrm{L}), \eta$ is the porosity $\left(\mathrm{L}^{3} \mathrm{~L}^{-3}\right)$ and $\theta$ is the soil moisture $\left(\mathrm{L}^{3} \mathrm{~L}^{-3}\right), c$ is the actual groundwater level and $b$ is the new groundwater level. On the other hand, if $Q_{\text {in(out),A }}$ is outflow, than

$\left|Q_{\text {in (out) }, A}\right|=\frac{\sum_{b<k \leq c-1}\left(Z_{k+1}-Z_{k}\right)\left(\eta_{k+1}-\theta_{\mathrm{fc}_{k+1}}\right)}{\Delta t_{\text {sim }}}$

where $\theta_{\mathrm{fc}}$ is the soil moisture at field capacity $\left(\mathrm{L}^{3} \mathrm{~L}^{-3}\right)$.

Moreover, we assume that if the soil in the floodplains adjacent to the river reaches will be completely saturated, i.e. "groundwater head" in the floodplains will rise above the 
terrain surface, the excess water does not flow into the river course, because it will be temporarily stored on the floodplain surface and then evaporate. We consider this assumption being appropriate because the floodplains are usually very wide and the depth of possible surface excess water is very shallow (a few centimetres at most). Therefore, we do not model in detail flow processes on the floodplain, instead assume that this excess water will evaporate soon.

\subsection{Stream-aquifer interaction calculation}

The stream-aquifer interaction term per unit of length of channel $I_{\mathrm{RA}}\left(\mathrm{L}^{3} \mathrm{~T}^{-1} \mathrm{~L}^{-1}\right)$ (Sect. 2.1) can be estimated by

$I_{\mathrm{RA}}=\left\{\begin{array}{l}-\min \left[\bar{h} s / \Delta t_{\text {sim }} ;\left|f^{*}\right|\right] \cdot \bar{P} s, \text { for } f^{*}<0 \\ f^{*} \cdot \bar{P} s, \text { for } f^{*} \geq 0\end{array}\right.$

where $\bar{h} s$ and $\bar{P} s$ are the average stream water stage and wetted perimeter, respectively, and $f^{*}$ is the potential infiltration determined in Sect. 2.2, as long as the stream-aquifer column is not saturated. Once the stream-aquifer layer is saturated, then $f^{*}$ is calculated as follows

$f^{*}=\frac{\Delta h^{*}}{\Delta t_{\mathrm{sim}}}$

where $\Delta h^{*}$ is the increase or decrease difference of the hydraulic head in the stream-aquifer column determined using Eq. (21) in Sect. 2.4.

If all the available stream water is to be infiltrated, then we apply no flood wave routing and set the predicted stream discharge and wetted cross-sectional area (related to stream water stage) equal to zero, in order to avoid numerical fluctuations when we use the stream-aquifer interaction term in the flood wave routing.

\subsection{Required input data, boundary conditions and model parameters}

In this section, we summarize the initial conditions, the boundary conditions and the model parameters of the approach presented in the previous sub-sections. The initial conditions for the flood wave routing of the river system are the initial stream discharge, wetted area, wetted perimeter and water level. The soil moisture in the unsaturated zone and the groundwater level in the aquifer columns (see Fig. 1) are also required initially to run the model.

The streamflow series of the uppermost river sections (see Fig. 1, river system) are the external boundary conditions for the flood wave routing in the river system (Sect. 2.1), while the lowest boundary conditions are not necessary to run it (Sect. 2.1). The groundwater flow model of the aquifer system (Fig. 1) can have the groundwater (in)outflows as the uppermost boundary condition (Sect. 2.5). In contrast, its downmost boundary condition is defined as no-flow or assuming that the gradient of the downmost aquifer unit is equal to its closest upstream one (see Sect. 2.5). The internal boundary conditions of the groundwater flow model are the groundwater pumping and the transpiration in the aquifer units (Sect. 2.5).

In the case of simulation at the basin-scale, one can include the surface flow from the small tributaries or from the hillslopes between the river cross-sections for the flood wave routing (Sect. 2.1) and the in-channel potential soil evaporation and evapotranspiration for the vertical soil water redistribution model (Sect. 2.3) as internal boundary conditions.

The parameters required to run the channel transmission losses model using all its model components are shown in Table 1. The simulation domain, where the model parameters are distributed, is provided after a spatial discretization of the case study (basin or river reach) into the model components (see Fig. 1), e.g. main river with reaches and cross-sections, aquifer units with (stream-)aquifer columns and soil layers per aquifer column.

Considering the variability of processes covered by this model we think that the model has a relatively small, but necessary, number of parameters. The parameters of the river systems may be derived from digital elevation models and topographical surveys, and those of the aquifer units and soil layers from hydrogeological and soil maps, stratigraphic data and by using pedo-transfer functions and literature data. Consequently, we expect to be able to apply our model for data-scarce areas in drylands (see next section).

\section{Case studies of the channel transmission losses model}

We evaluated our channel transmission losses model for two stream reaches with different scales and dominant processes: a large reach of the Middle Jaguaribe River (MJR), Ceará, Brazil and a much smaller one in the Walnut Gulch Experimental Watershed (WGEW), Arizona, USA. The data description of these sites and their parametrization are provided in the following sub-sections. The reason why we chose these two particular river case studies was to demonstrate the general applicability of the model for water planning and management in different types of data-scarce dryland rivers, i.e. to predict the streamflow volume and peak in the MJR (flow events in the rainy season) and in the WGEW (in case of convective storm rainfall/flash-flood events). This prediction was based on the specific perceptual hydrological models of the study sites, without performing any parameter calibration procedure. Therefore, we emphasise that it is not intended to reach a "best fit" with measured hydrographs, rather to achieve a profound hydrological system understanding, to enable the simulation of the overall system's response without calibration. This means that the model is not suited for, for example, flood forecasting, where the timing of the flood peak is highly relevant. 
Table 1. Required parameters for the channel transmission losses model (when using all sub-models).

\begin{tabular}{|c|c|}
\hline Component & Parameter \\
\hline River system & $\begin{array}{l}\text { Area }\left(\mathrm{L}^{2}\right) \text {, perimeter }(\mathrm{L}) \text {, and elevation }(\mathrm{L}) \text { of cross sections } \\
\text { Channel length }(\mathrm{L}) \\
\text { Sinuosity coefficient }(-)\end{array}$ \\
\hline Aquifer unit & $\begin{array}{l}\text { Number of aquifer columns }(-) \\
\text { Location of stream-aquifer column }(-) \\
\text { Aquifer column width (L) } \\
\text { Number of soil layers per aquifer column }(-)\end{array}$ \\
\hline Soil layer & $\begin{array}{l}\text { Vertical/lateral/parallel saturated hydraulic condutivity }\left(\mathrm{L} \mathrm{T}^{-1}\right) \\
\text { Wetting front suction }(\mathrm{L}) \\
\text { Porosity }\left(\mathrm{L}^{3} \mathrm{~L}^{-3}\right) \\
\text { Field capacity }\left(\mathrm{L}^{3} \mathrm{~L}^{-3}\right) \\
\text { Permanent wilting point }\left(\mathrm{L}^{3} \mathrm{~L}^{-3}\right) \\
\text { Residual water content }\left(\mathrm{L}^{3} \mathrm{~L}^{-3}\right) \\
\text { Poro-size-distribution index }(-)\end{array}$ \\
\hline
\end{tabular}

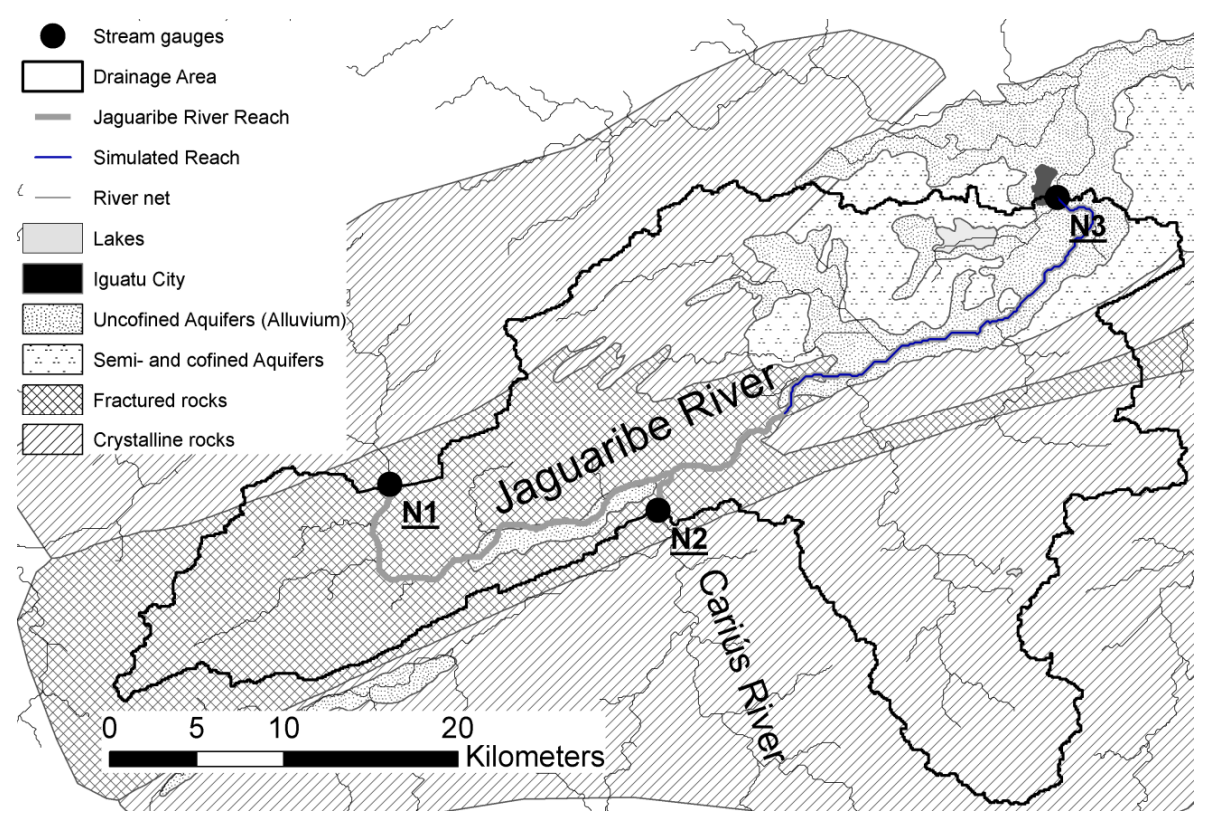

Fig. 3. Jaguaribe River reach studied by Costa et al. (2012). The hydrogeological map was adapted from IBGE (2003).

\subsection{Middle Jaguariber River (MJR), Ceará, Brazil}

\subsubsection{Data and parametrization}

We simulated a losing/gaining, hydraulically connected $30 \mathrm{~km}$ reach of the Middle Jaguaribe River, Ceará, NEBrazil, which drains a catchment area of $20000 \mathrm{~km}^{2}$. The Jaguaribe River basin's (total area $74000 \mathrm{~km}^{2}$ ) hydrology is determined by an annual cycle of rainy and dry seasons, which are driven mainly by the position of the Intertropical Convergence Zone and secondarily by cold fronts from the South Atlantic (Xavier, 2001; Werner and Gerstengarbe, 2003). The basin upstream the MJR receives annual precipitation between $400 \mathrm{~mm}$ (in the $\mathrm{SW}$ ) to $800 \mathrm{~mm}$ (in the NE), most of which falls in the months between December and May (van Oel et al., 2008). The areal potential evaporation (class A pan) amounts to $2200 \mathrm{~mm} \mathrm{yr}^{-1}$. Temporal rainfall variability is highly significant on a suite of scales: interannual variability, seasonal variability and variability at the time scale of a week.

The simulated reach is dominated by unconfined aquifers (Fig. 3) belonging to an alluvium with a $20 \mathrm{~m}$ average depth 
and composed of layers of fine and coarse sand, gravel and clay (IBGE, 2003). According to Costa et al. (2012), on the one hand, during the dry and at the beginning of the rainy seasons, no pre-event river flow is expected and streamflow events will create predominantly vertical infiltration into the alluvium. On the other hand, at the middle and end of the rainy seasons, river flow sustained by base flow occurs before and after streamflow events and lateral infiltration into the alluvium plays a major role during events. Moreover, most channel transmission losses are certainly infiltrated only through the cross section of the main channel and not through the floodplains (Costa et al., 2012).

We assumed that the inflow from the drainage area between the stream gauges can be neglected for medium and large floods in the Jaguaribe River reach, because (a) the drainage area between the gauges is about 20 times less than the upstream catchment area and (b) it has about 130 surface reservoirs in its drainage network (based on Costa et al., 2012), which retains almost all of generated runoff.

Measurements on the initial moisture of the aquifersystem were not available. However, since at the middle of the rainy seasons river flow is expected to be sustained by base flow, we may assume the riverine groundwater level to be close to the river bed at the middle of the rainy seasons, for which we applied the model. We assumed from Costa et al. (2012) that the actual inflow into the simulated reach is a sum of the actual streamflow measured at the N2 stream gauge, close to the confluence of the Cariús river into the Jaguaribe River, and the one-day-before streamflow measured at the N1 stream gauge in the Jaguaribe River (see Fig. 3). The simulated output streamflow was compared to the streamflow measured at the N3 stream gauge in the Jaguaribe River.

We used alluvial stratigraphy data, 15 boreholes and one electrical resistivity survey (Carneiro, 1993), and alluvium extension information from a hydrogeological map (Fig. 3) to derive the aquifer units (see Fig. 1). We used remote sensing-based data available from Costa et al. (2012) to delineate the channel length and the maximum channel width, whereas field observation provided the maximum channel depth. Then, we derived stream cross-sectional areas by assuming a triangular channel cross-sectional area. We did not account for infiltration into floodplains; since for our example it is not considered relevant for channel transmission losses, as discussed above in this section.

The simulated MJR was spatially modelled (see Fig. 1) as one basin system, which has one river with 4 reaches and 5 sections. Its aquifer system was formed by 4 units containing respectively $7,17,13$ and 21 (stream-)aquifer columns from up- to downstream. The typical up-to-down stratigraphy of an aquifer column was: sandy loam (topsoil), fine to coarse sand (1st alluvial layer), coarse gravel and very coarse sand (2nd alluvial layer) and silty clay (boundary condition), being the last three for the stream-aquifer columns. Moreover, the soil layer interval was set at $0.2 \mathrm{~m}$ for all (stream-)aquifer columns. The texture of the aquifer was used to derive its soil physical properties, such as saturated hydraulic conductivity and porosity, obtained from experimental tables published in Rawls et al. (1993) and Dingman (2002).

The time step of the calculation, which gave the best numerical stability of flood wave routing and, consequently, used for this simulation, was $12 \mathrm{~h}$. Since the original input time series were not sampled every $12 \mathrm{~h}$, but only daily, we had to disaggregate them.

\subsubsection{Model application}

We selected three rainy seasons from 2005 until 2010, namely 2005, 2009 and 2010, which met the conditions described in the previous sub-section. Figure $4 \mathrm{a}-\mathrm{c}$ shows the input and observed output streamflow series of those rainy seasons.

Using those rainy seasons, we evaluated which model structure would provide the best simulation, i.e. the minimum of both root mean squared error (RMSE) and mean absolute error (MAE) of peak and event volume time series. Using the same parameter set and the spatial discretization, which were derived without calibration as shown in the previous sub-section, we defined three possible model structures: (a) flood wave routing only, i.e. no aquifer system, and no transmission losses, respectively (FW); (b) flood wave routing with lateral (stream-)aquifer dynamics, but without groundwater flow parallel to the river course, $(\mathrm{FW}+\mathrm{LD})$; and (c) the same as (b) but now including parallel groundwater flow $(\mathrm{FW}+\mathrm{LD}+\mathrm{GW})$. Figure $5 \mathrm{a}-\mathrm{c}$ shows the simulated and observed output streamflow series.

The FW-based model overestimated both the streamflow peak and the volume. The $(\mathrm{FW}+\mathrm{LD})$ - and $(\mathrm{FW}+\mathrm{LD}+\mathrm{GW})$-based models predicted similar peaks, but the $(\mathrm{FW}+\mathrm{LD})$-based simulated hydrograph decreased more sharply during the recession flow than the $(\mathrm{FW}+\mathrm{LD}+\mathrm{GW})$ based one. The models' performance is shown in Table 2 .

The $(\mathrm{FW}+\mathrm{LD})$ - and $(\mathrm{FW}+\mathrm{LD}+\mathrm{GW})$-based models had comparable performance and both were better than the FWbased. Because the $(\mathrm{FW}+\mathrm{LD}+\mathrm{GW})$-based model had the most similar behaviour to the observed hydrographs than the (FW + LD)-based one, we consider the (FW + LD + GW)based model structure as the best suited for this study site.

\subsection{Walnut Gulch Experimental Watershed, Arizona, USA}

\subsubsection{Data and parametrization}

We simulated here a losing, hydraulically disconnected $1.5 \mathrm{~km}$ channel reach in the Walnut Gulch Experimental Watershed (WGEW), Arizona, USA, from the flume FL008 (input flow) to the FL006 (output flow) (Fig. 6). Based on previous publications (e.g. Renard, 1970; Goodrich et al., 2004; 


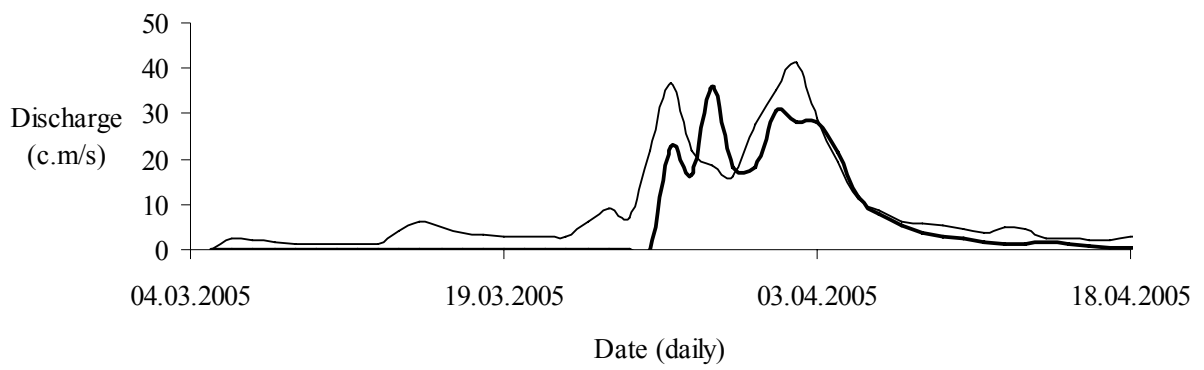

- Input - Observed Output

(a)

2009

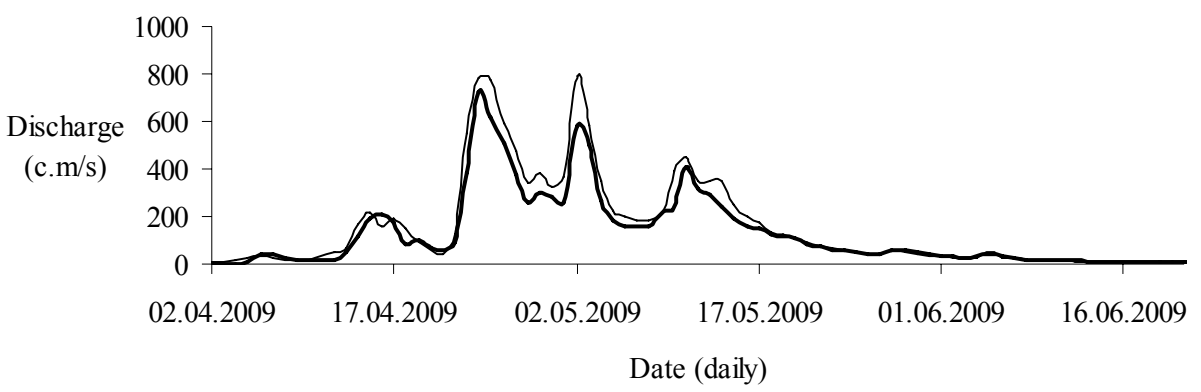

Input - Observed Output

(b)

2010

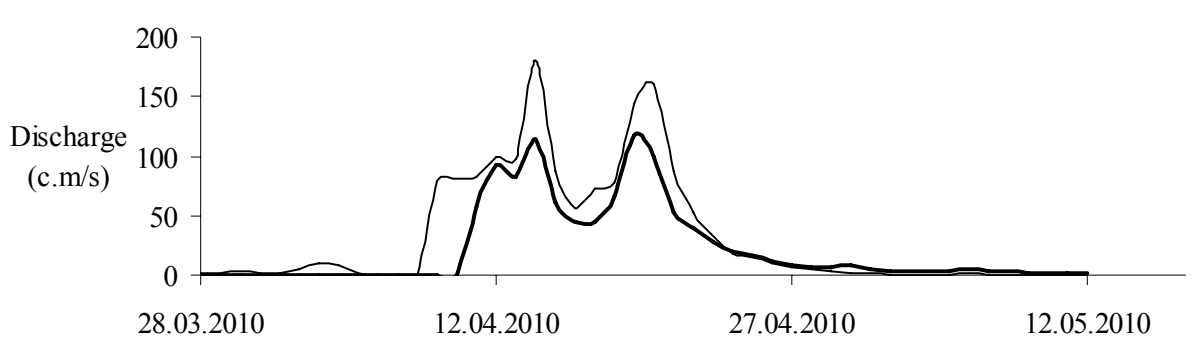

Date (daily)

Fig. 4. Input and observed output streamflow series of the studied reach of the Jaguaribe River reach in (a) 2005 , (b) 2009 and (c) 2010.

Renard et al., 2008; Stone et al., 2008; Emmerich, 2008; Osterkamp, 2008), we assumed that streamflow infiltrates into an sandy alluvium with enough depth such that it never becomes completely saturated during a streamflow event, because depth to groundwater within the WGEW ranges from $\sim 50 \mathrm{~m}$ at the lower end to $\sim 145 \mathrm{~m}$ in the central portion of the watershed (Goodrich et al., 2004; also see Spangler, 1969). Hydrological data and geo-information were made available at http://www.tucson.ars.ag.gov/dap/.
We selected hydrographs from streamflow events in which:

1. the input flow was only registered by the selected upstream flume (FL008);

2. the event volume, duration and peak flow at the selected upstream flume (FL008) were greater than at the downstream flume (FL006); 


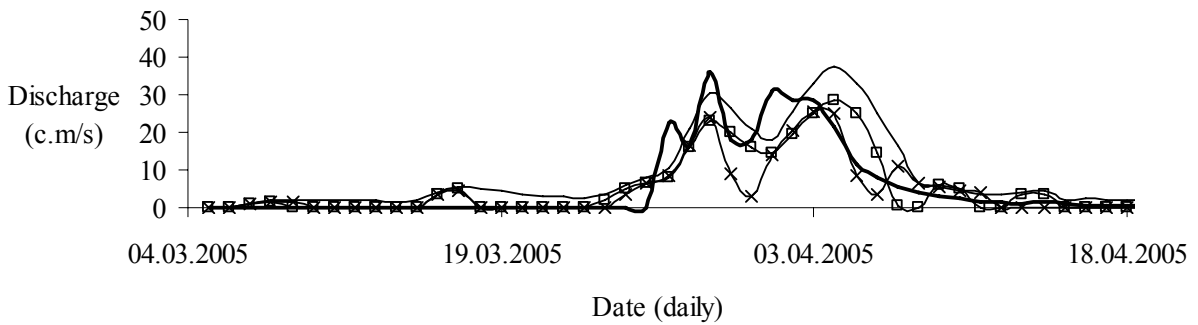

- Observed Output $-\mathrm{FW} \rightarrow-\mathrm{FW}+\mathrm{LD} \rightarrow-\mathrm{FW}+\mathrm{LD}+\mathrm{GW}$

(a)

2009

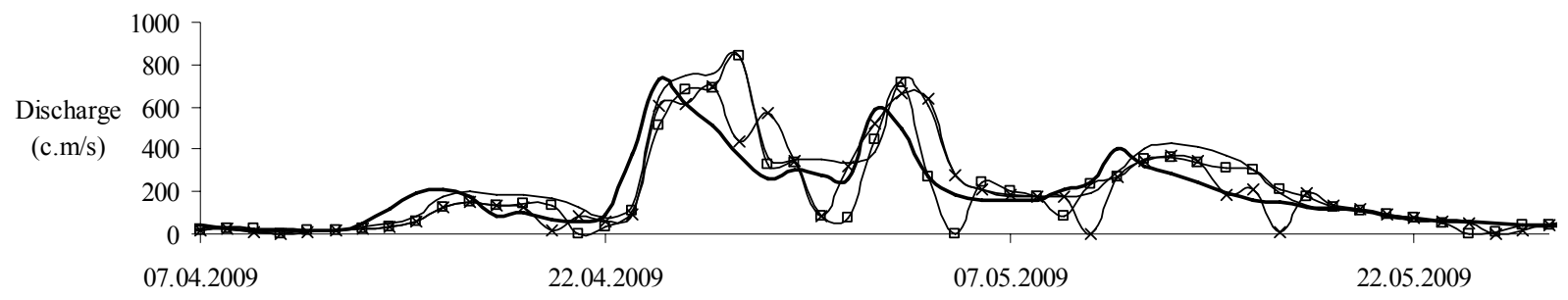

Date (daily)

(b)

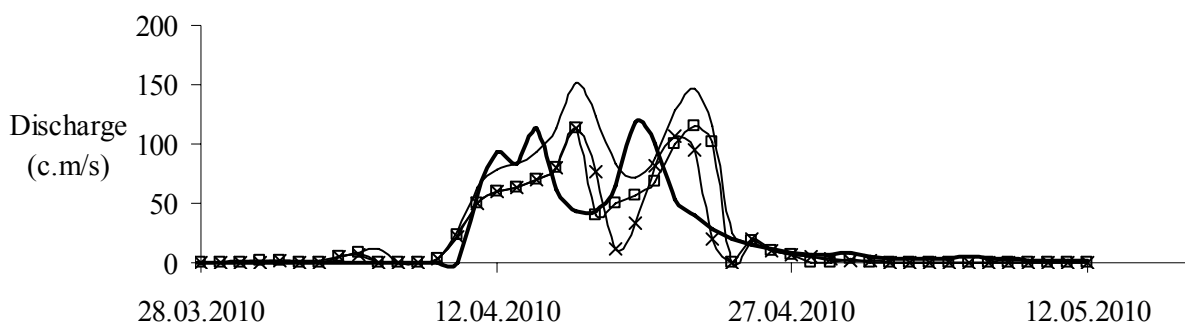

Date (daily)

- Observed Output $-\mathrm{FW} \rightarrow$ FW $+\mathrm{LD} \rightarrow-\mathrm{FW}+\mathrm{LD}+\mathrm{GW}$

(c)

Fig. 5. Simulated and observed output streamflow series of the studied reach of the Jaguaribe River in (a) 2005, (b) 2009 and (c) 2010. The three model structures tested were: (1) only flood wave routing, i.e. no aquifer system, (FW); (2) flood wave routing with lateral (stream)aquifer dynamics, but without groundwater flow parallel to the river course, (FW + LD); and (3) equal to the last one, but now with parallel groundwater flow $(\mathrm{FW}+\mathrm{LD}+\mathrm{GW})$.

3. the soil moisture content of the underlying alluvium could be assumed close to the residual moisture content, i.e. at the beginning of the rainy season or after a long time between runoff events during the rainy season, since no soil moisture data of the underlying alluvium were made available.
Maximum channel cross-sectional area and channel width were derived by stream channel morphology relationships provided by Miller et al. (2003). The stream cross-sectional areas were then derived assuming a triangular channel crosssectional area. We did not account for floodplains, because no data about them were available and also because we considered them to be of minor importance for transmission 


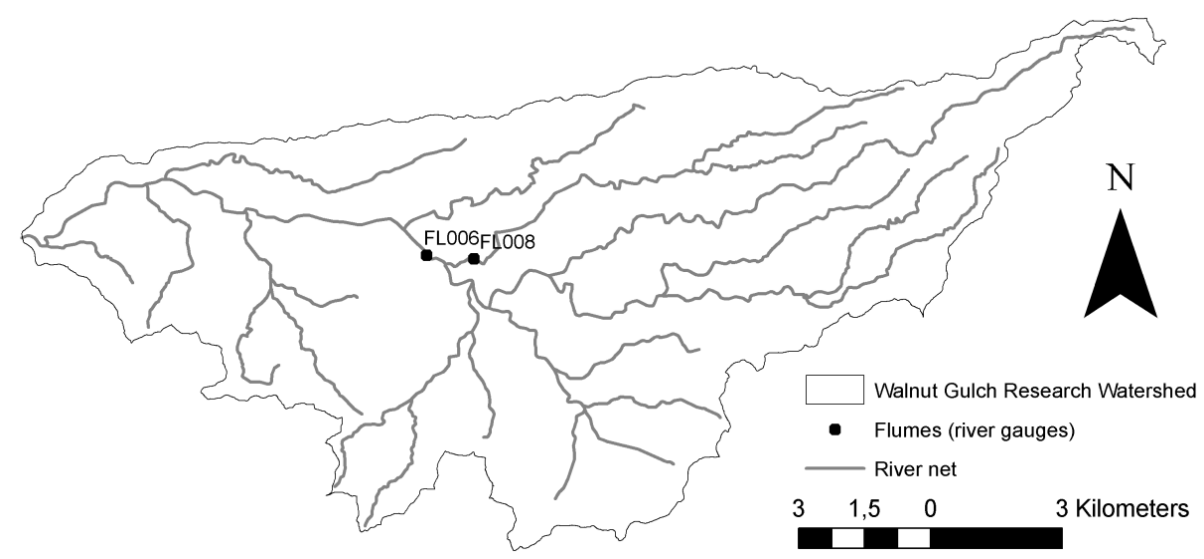

Fig. 6. Walnut Gulch Research Watershed (PCS: NAD83 and GCS: North American 1983) based on data made available at http://www. tucson.ars.ag.gov/dap/.

Table 2. Mean absolute error (MAE) and root mean square error (RMSE) of the three model structures tested: (1) only flood wave routing, i.e. no aquifer system, (FW); (2) flood wave routing with lateral (stream-)aquifer dynamics, but without groundwater flow parallel to the river course, $(\mathrm{FW}+\mathrm{LD})$; and (3) equal to the last one, but now with parallel groundwater flow $(\mathrm{FW}+\mathrm{LD}+\mathrm{GW})$.

\begin{tabular}{lccccc}
\hline \multirow{2}{*}{$\begin{array}{l}\text { Model } \\
\text { structure }\end{array}$} & \multicolumn{2}{c}{ Volume } & & \multicolumn{2}{c}{ Peak } \\
\cline { 2 - 3 } \cline { 5 - 6 } & $\begin{array}{c}\text { MAE } \\
(\%)\end{array}$ & $\begin{array}{c}\text { RMSE } \\
\left(10^{6} \mathrm{~m}^{3}\right)\end{array}$ & & $\begin{array}{c}\text { MAE } \\
(\%)\end{array}$ & $\begin{array}{c}\text { RMSE } \\
\left(\mathrm{m}^{3} \mathrm{~s}^{-1}\right)\end{array}$ \\
\hline FW & 41 & 96 & & 20 & 74 \\
FW + LD & 10 & 31 & & 12 & 36 \\
FW + LD + GW & 4 & 41 & & 13 & 67 \\
\hline
\end{tabular}

losses in that stream reach. Consequently, the floods had to be assumed as sub-bank flows.

The simulated reach in the WGEW was spatially modelled (see Fig. 1) as one basin system, which has one stream with 3 reaches and 4 sections. Its aquifer system was formed by 3 units, each containing only one stream-aquifer column. The aquifer system was assumed to be uniformly sandy. Moreover, its soil layer interval was set $0.1 \mathrm{~m}$ for all streamaquifer columns. The texture of the aquifer was used to derive its soil physical properties, such as saturated hydraulic conductivity and porosity, obtained from experimental tables published in Rawls et al. (1993) and Dingman (2002).

The time step of calculation, which gave the best numerical stability of flood wave routing and which was consequently used for this simulation, was $2 \mathrm{~min}$. Since the original input time series were not sampled for every $2 \mathrm{~min}$, we had to resample them.

\subsubsection{Model application}

We selected 6 streamflow events which met the conditions described in the previous sub-section, in order to simulate the channel transmission losses from flume FL008 to flume FL006 (Fig. 6) using the parameters set and the spatial discretization derived without calibration, as already explained in the previous sub-section. Table 3 compares the observed and simulated flow volume and peak of those events and shows the differences between the observed and simulated peak times.

The volume of the events was clearly always underestimated, its MAE being equal to $0.4 \times 10^{3} \mathrm{~m}^{3}$ and its RMSE equal to $0.5 \times 10^{3} \mathrm{~m}^{3}$. The peak flow of the events was better predicted than its volume, where its error did not show a clear trend, its MAE being equal to $0.2 \mathrm{~m}^{3} \mathrm{~s}^{-1}$ and its RMSE equal to $0.3 \mathrm{~m}^{3} \mathrm{~s}^{-1}$. We show the best and the worst predicted output hydrographs, which occurred on 29 August 1972 (Fig. 7) and on 2 August 1968 (Fig. 8), respectively, as follows: the simulation results made clear some distinct problems with the hydrograph shape (see e.g. Fig. 7, but also Fig. 5c for the MJR) and some pronounced errors between the observed and predicted peak time of the events simulated in the WGEW (Table 3). This is explained because the flow velocity in our simplified flood wave routing (Sect. 2.1) is controlled by the channel cross-sections, which were approximated through simple relationships. This only vague approximation of the channel cross-sections can be considered as a typical problem of dryland regions. Therefore, the inherent data scarcity of the channel morphology will inevitably lead to uncertainties in the timing of the hydrograph.

\section{Model reliability}

Important model uncertainties in hydrological modelling may be classified in three fields: numerical or mathematical 
Table 3. Comparison between the observed and simulated volume and peak flow and the differences between the observed and simulated peak times of the selected events from the studied $1.5 \mathrm{~km}$ reach in the Walnut Gulch Experimental Watershed, Flume FL006.

\begin{tabular}{|c|c|c|c|c|c|}
\hline \multirow[t]{2}{*}{ Event } & \multicolumn{2}{|c|}{ Volume $\left(10^{3} \mathrm{~m}^{3}\right)$} & \multicolumn{2}{|c|}{ Peak $\left(\mathrm{m}^{3} \mathrm{~s}^{-1}\right)$} & \multirow{2}{*}{$\begin{array}{l}\text { Peak time error } \\
\left(\min \mathrm{km}^{-1}\right)\end{array}$} \\
\hline & Observed & Simulated & Observed & Simulated & \\
\hline 2 Aug 1968 & 2.0 & 1.0 & 1.3 & 0.7 & -6.7 \\
\hline 28 Aug 1969 & 0.0 & 0.1 & 0.0 & 0.1 & $\mathrm{na}^{*}$ \\
\hline 24 Jul 1970 & 1.2 & 0.7 & 0.8 & 0.5 & -2.7 \\
\hline 28 Jul 1972 & 0.5 & 0.2 & 0.3 & 0.3 & -3.3 \\
\hline 29 Aug 1972 & 1.2 & 0.6 & 0.8 & 0.8 & 6.0 \\
\hline 7 Aug 1983 & 0.0 & 0.0 & 0.0 & 0.1 & na* \\
\hline
\end{tabular}

* not applicable

08.29 .1972

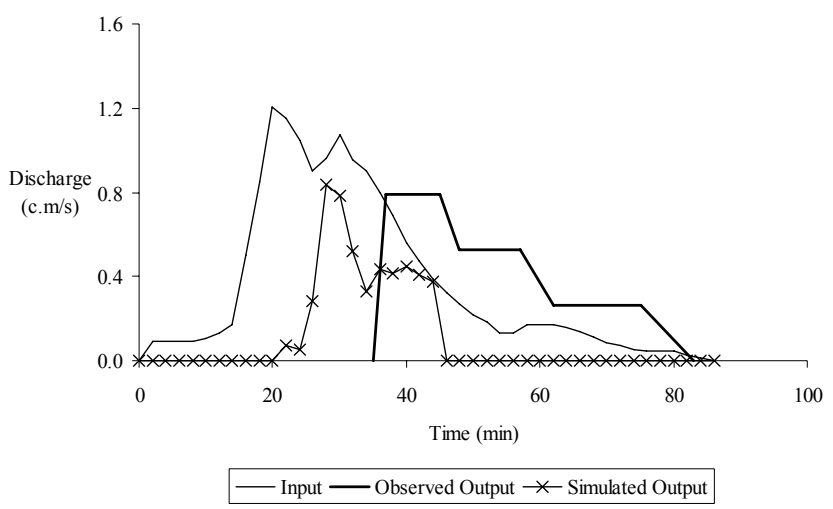

Fig. 7. The best predicted output hydrograph for the studied reach in the Walnut Gulch Research Watershed (at Flume FL006).

uncertainty (dealing with numerical stability and accuracy of the adopted solvers for the process equations), parameter uncertainty (including individual and combined sensitivity of model parameters, multiple-valid parameter sets, sub-scale parameter variability) and structural uncertainty (comprising the selection of model processes and their interactions, effects of uncertain initial and boundary conditions and/or the model-representation of the simulation domain).

The model structure uncertainty was analyzed previously for the Jaguaribe River reach and was negligible for the WGEW's stream.

In this section, we evaluate the numerical and the model parameter uncertainty by (a) analysis of numerical stability and accuracy of the subsurface simulations, and (b) individual sensitivity analysis of the model parameters; and an overall (combined) model parameter uncertainty analysis. The structural uncertainty has been approached to a limited extend in the previous section, where we discussed the influence of different process representations of the subsurface (i.e. with/without considering interactions of the groundwater with channel water and with/without considering parallel

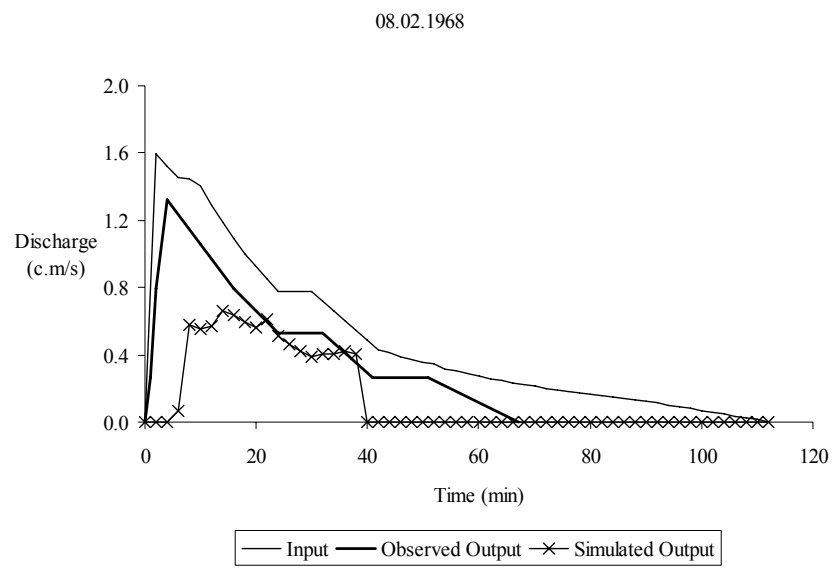

Fig. 8. The worst predicted output hydrograph for the studied reach in the Walnut Gulch Research Watershed (at Flume FL006).

groundwater flow and by prescribing initial and boundary conditions according to the available field data and the perceptual hydrological models of the river reaches). We think that a more comprehensive elaboration of the structural uncertainty (e.g. by choosing a variety of different possible interpretations of hydro-geological structures or by applying different hydrological process formulations) would clearly go beyond the scope of this paper.

\subsection{Numerical issues}

Here we present simulation results, which enable us to evaluate whether the spatial and temporal discretization (Sects. 3.1.1 and 3.2.1) and the numerical approximations (Sect. 2) are such that the model is numerically stable and accurately represents the governing equations. Therefore, we selected some simulations of the subsurface systems, i.e. the unsaturated zone in the WGEW and the saturated zone in the MJR, to be presented here. We do not show all results of the subsurface systems because this would not add more information. 

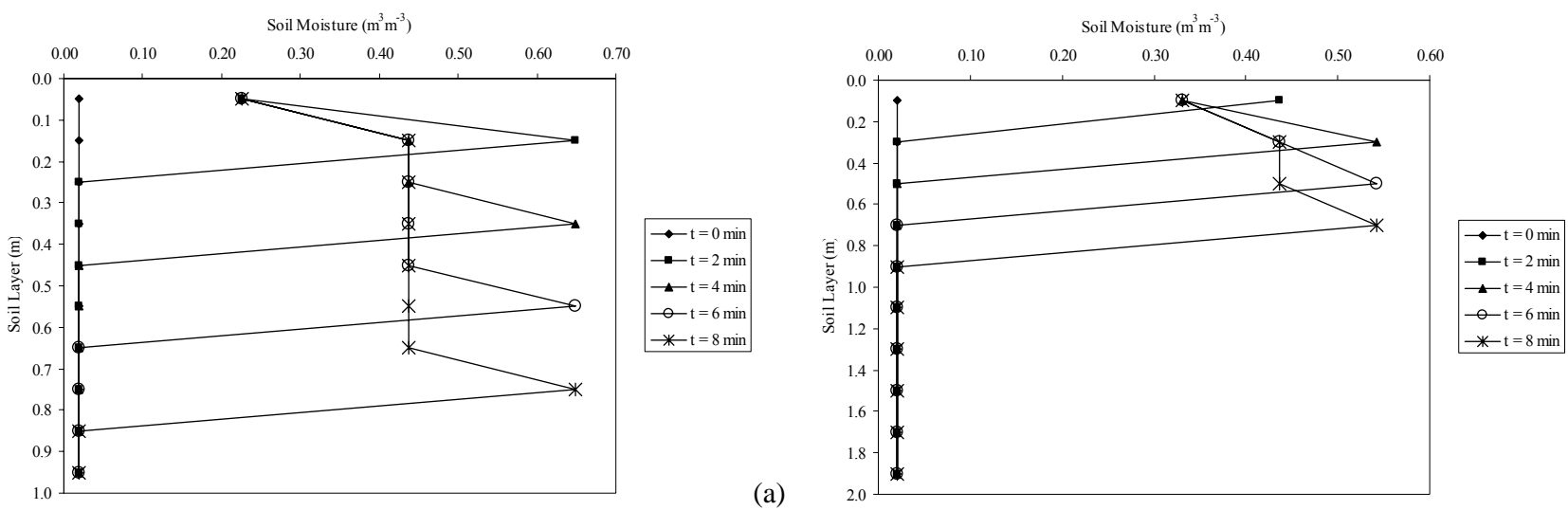

(b)
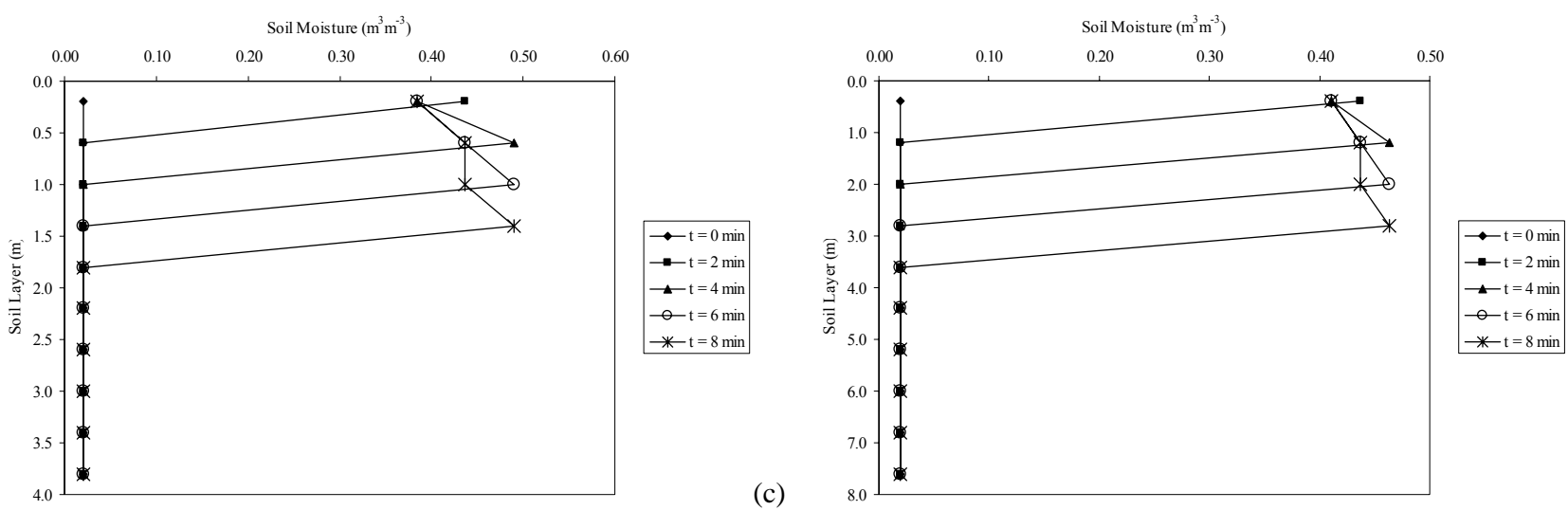

(d)

Fig. 9. The soil moisture simulation of the unsaturated zone of the uppermost reach during the event on 28 July 1972 in the Walnut Gulch Research Watershed - time step equal to $2 \mathrm{~min}$ and soil layer interval (a) $0.1 \mathrm{~m}$, (b) $0.2 \mathrm{~m}$, (c) $0.4 \mathrm{~m}$ and (d) $0.8 \mathrm{~m}$.

\subsubsection{Unsaturated zone in the Walnut Gulch Experimental Watershed}

We present here the soil moisture simulation of the unsaturated zone of the uppermost stream reach (see Sect. 3.2.1 for the discretization) during the streamflow event on 28 July 1972 in the WGEW. We used a time step of $2 \mathrm{~min}$, which gave the best numerical stability for flood wave routing. Then, we assumed the soil layer intervals $0.1 \mathrm{~m}$, which was adopted for the previous application, $0.2 \mathrm{~m}, 0.4 \mathrm{~m}$ and $0.8 \mathrm{~m}$, respectively. Figures $9 \mathrm{a}-\mathrm{d}$ show the first $8 \mathrm{~min}$ of the soil moisture simulation, i.e. the propagation of the downward soil wetting.

The soil moisture simulation is governed by both the unsaturated stream infiltration model (Sect. 2.2) and the vertical soil water redistribution model (Sect. 2.3). While the stream water infiltrated through the soil column, the uppermost soil layer was never completely saturated and the lowest wetted soil layer had always the greatest moisture (peak). The former can be explained by the hydraulic conductivity term $K_{k-(1 / 2)}^{j}$, which approaches zero in Eq. (16) for the uppermost soil layer. The latter seems to be inevitable if the moisture or the hydraulic conductivity between two soil layers is rather different. These numerical "artefacts" were smoother when the interval of the soil layer increased but, consequently, the infiltrated water into the soil column also reached a higher depth.

Instead of using the harmonic mean between the hydraulic conductivity of the soil layers (see Eq. 16), one can adopt the arithmetic mean (see e.g. van Dam and Feddes, 2000). Considering now the arithmetic mean and a soil layer interval equal to $0.2 \mathrm{~m}$, we found that those numerical artefacts were even smoother (Fig. 10). Moreover, there were no significant changes in the simulated streamflow volume and peak (smaller than $5 \%$ ) between 0.1 and $0.2 \mathrm{~m}$ soil layer interval and using harmonic or arithmetic mean. However, we found $+30 \%$ and $+16 \%$ difference in simulated volume and peak, respectively, between 0.1 and $0.4 \mathrm{~m}$ intervals and $+42 \%$ and $+26 \%$ between 0.1 and $0.8 \mathrm{~m}$.

\subsubsection{Saturated zone in the Middle Jaguaribe River}

We present the groundwater and stream levels' simulation of the farthest downstream stream reach of the MJR (see 


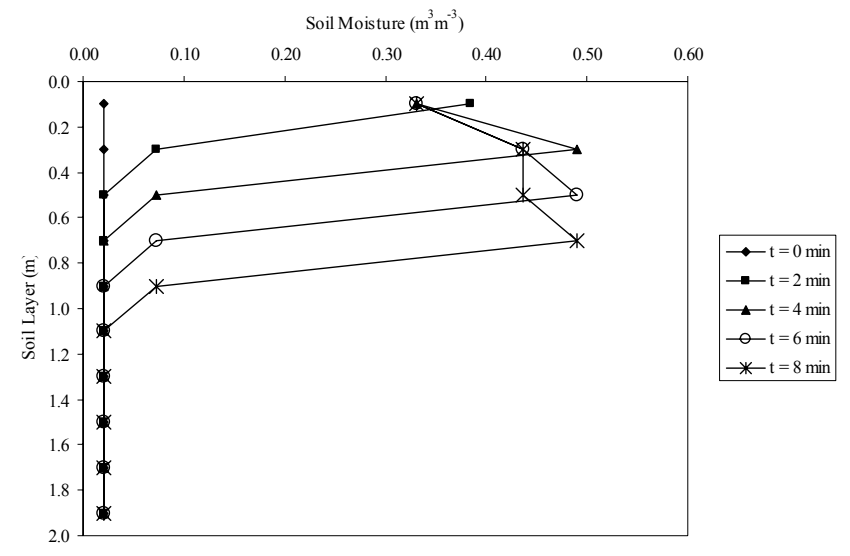

Fig. 10. The soil moisture simulation of the unsaturated zone of the uppermost reach during the event on 28 July 1972 in the Walnut Gulch Research Watershed (time step equal to $2 \mathrm{~min}$ and soil layer interval $0.2 \mathrm{~m}$ ), but using the arithmetic mean in Eq. (16), instead of the harmonic mean.

Sect. 3.1.1 for the temporal and spatial discretization) during the rainy season in 2010 in the Jaguaribe River. The width of the aquifer columns was defined as half the width of the stream-aquifer columns for all the stream reaches.

Figure 11a shows the groundwater and stream levels' simulation using the best model structure found previously for the streamflow series, i.e. the combination of the flood wave routing, the lateral river-aquifer dynamics and the groundwater flow parallel to the river course (Sect. 3.1.2). These simulation results showed the flow from the river (stream-aquifer column 11 in Fig. 11a) into the surrounding groundwater in the times equal to $15,25,30$ and 34 days and the flow from the groundwater into the river during the rest of the times, as we expected. However, during the infiltration from the river into the groundwater, the groundwater levels in the most distant aquifer columns (seen from the stream-aquifer column) decreased approximately from $16 \mathrm{~m}$ to $14 \mathrm{~m}$ (see Fig. 11a), which is probably too much for a period of 20 days in this environment. A large groundwater outflow from the aquifer unit in the farthest downstream reach can explain this decrease in groundwater level. In order to check this hypothesis, we plotted the simulation of the model structure without considering the groundwater flow parallel to the river course (Fig. 11b). The groundwater level of all the aquifer columns then works as expected. Thus, assuming the gradient of this to be equal to the unit closest to it upstream (see Sect. 2.5), we may overestimate its outflow. Nevertheless, the groundwater flow model needs to be taken into account to achieve the best fit for the streamflow series (Sect. 3.1.5).

\subsection{Individual parameter sensitivity analysis}

We carried out a classical parameter sensitivity analysis in order to guide the efforts on data acquisition and parameter calibration in future applications. We used for the parameter sensitivity analysis the following standard formulation

$\varphi_{i}=\frac{y\left(P_{i}\right)-y_{\text {reference }}}{y_{\text {reference }}}$

where $\phi$ is the sensitivity coefficient, $y$ is here a simulated variable, streamflow peak or event volume, and $P$ is a model parameter. To carry out the sensitivity analysis, we selected the driest and the wettest streamflow events, whose upstream flow reached the farthest downstream stream section.

\subsubsection{Middle Jaguariber River}

Once the $(\mathrm{FW}+\mathrm{LD}+\mathrm{GW})$-based model structure had presented the best simulation performance for streamflow volume and maximum peak, we chose the following set of parameters for sensitivity analysis: (a) porosity $\eta$ and (b) soil moisture at field capacity $\theta_{\mathrm{fc}}$, which are related to groundwater level computation (Eqs. 25 and 26); (c) lateral saturated hydraulic conductivity $K_{A}$ of column A, which is related to lateral (stream-)aquifer dynamics (Eq. 20); and (d) "parallel" saturated hydraulic conductivity $K_{u}$ of aquifer unit $u$, which is related to groundwater flow parallel to the river course (Eq. 23).

Streamflow volume and maximum peak simulated by the $(\mathrm{FW}+\mathrm{LD}+\mathrm{GW})$-based model for the years 2005 and 2009 were used as reference variables (see Eq. 29), because those years were the driest and the wettest. Then, we multiplied a variable factor with the original values of the parameters and ran the (FW + $\mathrm{LD}+\mathrm{GW})$-based model again, in order to estimate the sensitivity coefficients (Eq. 29) for streamflow volumes and maximum peaks.

The sensitivity was very small, i.e. the results did not vary with changes of porosity (range between $\theta_{\mathrm{fc}}$ and $1.5 \times \eta$ ) neither with changes of soil moisture at field capacity (range between $0.5 \times \theta_{\mathrm{fc}}$ and $\eta$ ). In contrast, the sensitivity was high due to changes in lateral and parallel saturated hydraulic conductivities. Figure 12a-b show the results of sensitivity analysis of those conductivity parameters for 2005 and Fig. 13a$\mathrm{b}$ for 2009 .

In general, high values of both saturated hydraulic conductivities showed little sensitivity to the reference simulation, because large fluxes between model units are restricted by their hydraulic gradient (see Eqs. 20 and 23) and the reference simulation was already driven by the hydraulic gradient between the model units.

The sensitivity coefficients of lateral and parallel saturated hydraulic conductivities can still be considered negligible for both streamflow volume and peak for parameter values greater than $50 \%$ of their original values. On the other hand, less than $50 \%$ of the original values of lateral and parallel saturated hydraulic conductivities, their sensitivity coefficients could no longer be considered negligible. However, from $50 \%$ to $10 \%$ of the original values, their sensitivity coefficient was between the range $[-0.20 ; 0.20]$. 

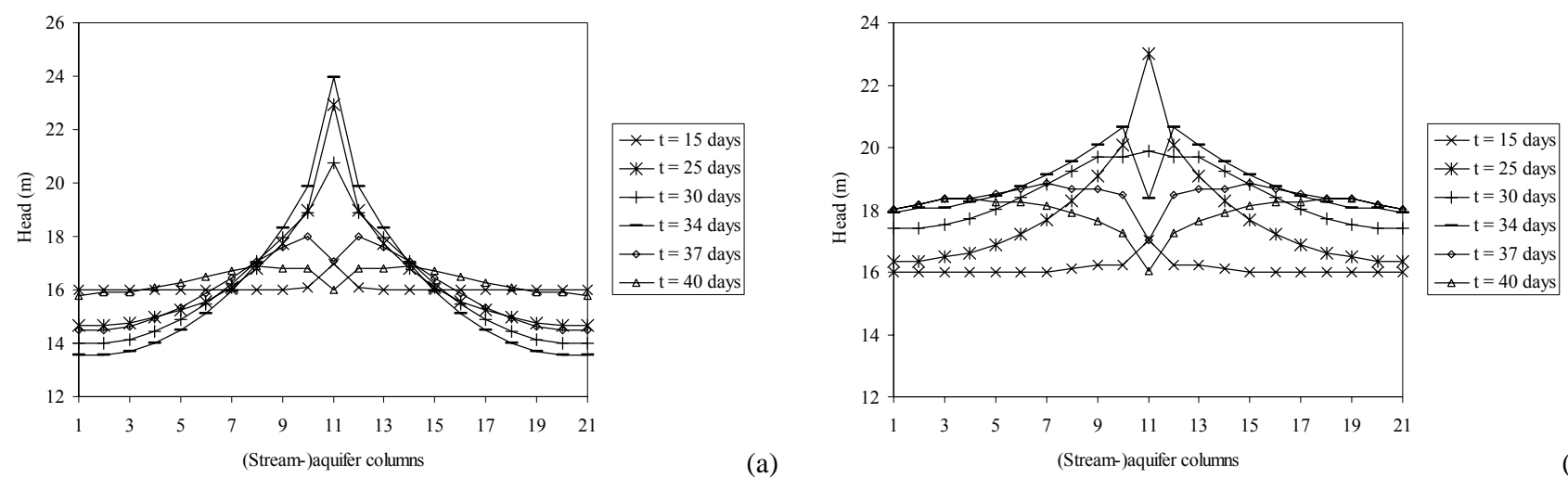

(b)

Fig. 11. The simulation of groundwater and river levels in the farthest downstream stream reach during the rainy season in 2010 in the Jaguaribe River. The streambed level is $16 \mathrm{~m}$ and the surface level $30 \mathrm{~m}$. (a) The stream-aquifer column is volume No. 11 in the $\mathrm{x}$-axis. The model structure was that which provided the best fit for the streamflow series (Sect. 3.1.2), i.e. including the simulation of flood wave routing, lateral river-aquifer dynamics and groundwater flow parallel to the river course. (b) The stream-aquifer column is volume No. 11 in the $\mathrm{x}$-axis. The model structure did not consider the groundwater flow parallel to the river course.

2005

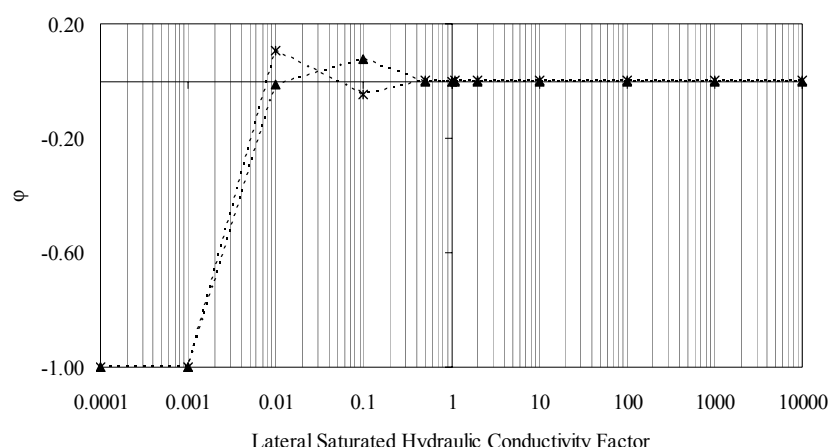

- Volume $\cdots *$ - $\cdots$ Peak

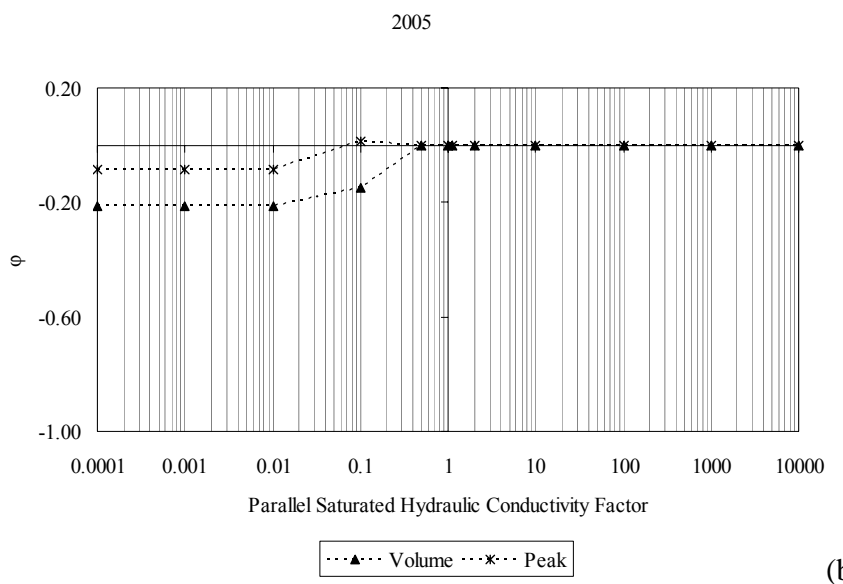

(b)

Fig. 12. Sensitivity analysis of (a) lateral saturated hydraulic conductivity and (b) parallel saturated hydraulic conductivity, where $\phi$ is the sensitivity coefficient (Eq. 28) and X-axis is the factor which was multiplied with the original values of the parameter (MLR, March to April 2005).

Even when parallel saturated hydraulic conductivity decreased to values less than $10 \%$ of its original values (Figs. $12 \mathrm{~b}$ and $13 \mathrm{~b}$ ), its sensitivity coefficients converged to a value between the aforementioned range. On the other hand, after lateral saturated hydraulic conductivity reached $1 \%$ of its original values (Figs. 12a and 13a), its sensitivity coefficient decayed rapidly to its lowest value of -1.00 . This agreed with the results of the case studies presented previously that the lateral (stream-)aquifer dynamics model is more relevant than the model of the groundwater flow parallel to the river course for simulating streamflow in the Jaguaribe River.

Therefore, the sensitivity showed the largest values with changes in lateral saturated hydraulic conductivity followed by parallel saturated hydraulic conductivity.

\subsubsection{Walnut Gulch Experimental Watershed}

We selected the following set of parameters to carry out the sensitivity analysis: soil moisture at field capacity $\theta_{\mathrm{fc}}$, pore-size-distribution index $\lambda$, porosity $\eta$, wetting front suction $\psi$ and saturated hydraulic conductivity $K_{\text {sat }}$. Streamflow volume and maximum peak simulated for the events on 28 July 1972 and 2 August 1968 were used as reference variables (see Eq. 29), because those were the driest and the wettest events. Then, we multiplied a variable factor with the original values of those parameters and ran the channel transmission losses model again, in order to estimate the sensitivity coefficients (Eq. 29) for streamflow volumes and maximum peaks. 
2009

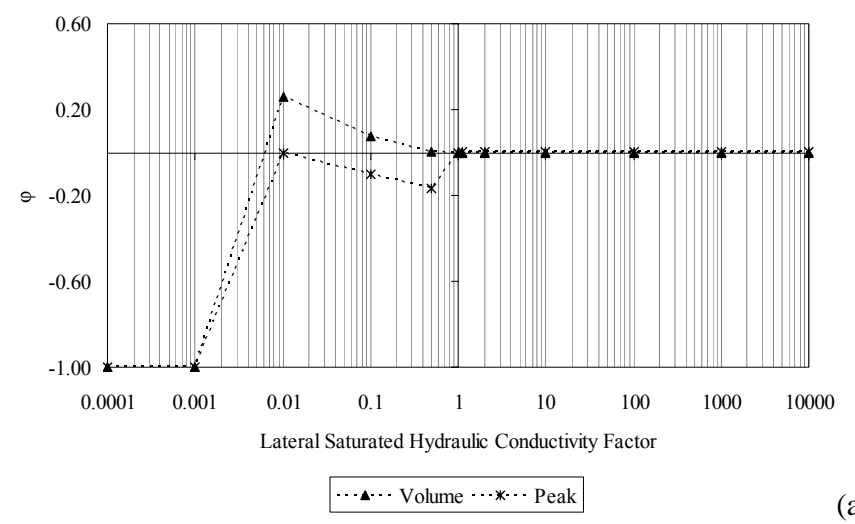

2009

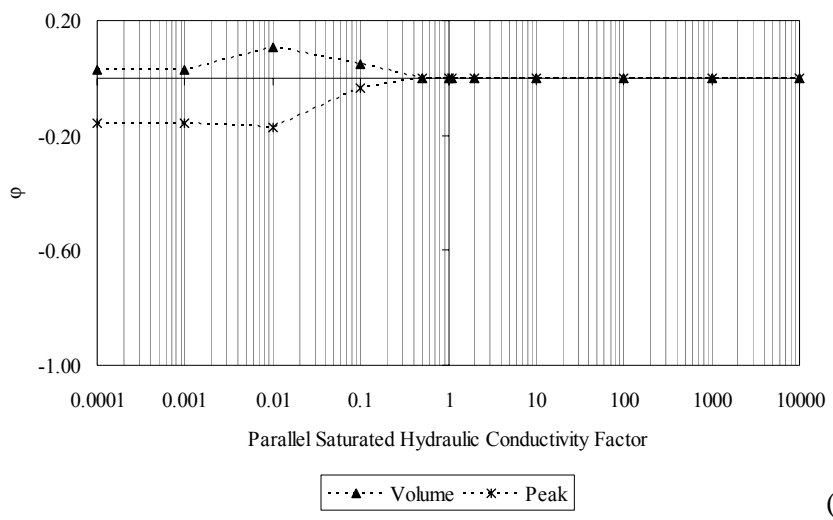

Fig. 13. Sensitivity analysis of (a) lateral saturated hydraulic conductivity and (b) parallel saturated hydraulic conductivity, where $\phi$ is the sensitivity coefficient (Eq. 29) and x-axis is the factor which was multiplied with the original values of the parameter (MLR, April to June 2009).

The sensitivity did not vary with changes in soil moisture at field capacity and pore-size-distribution index. In contrast, the sensitivity varied significantly with changes in porosity, wetting front suction and saturated hydraulic conductivity. Figure 14a-c show the results of sensitivity analysis of those parameters for 28 July 1972 and Fig. 15a-c for 2 August 1968.

The sensitivity showed the largest values with changes in saturated hydraulic conductivity followed by wetting front suction and porosity. The higher those parameters are, the smaller is their sensitivity, i.e. the higher the infiltration from the stream into the alluvium. However, fluctuations in that behaviour could be found for peak flow in relation to wetting front suction, which might be related to numerical instabilities.

The sensitivity coefficient reached its lowest value of -1.00 with a change of $+50 \%$ in the saturated hydraulic conductivity for both the streamflow volume and peak (Figs. 14c and 15c), whereas the sensitivity coefficient of the porosity remained between the range $[-0.30 ; 0.20]$ for the same change (Figs. 14a and 15a). The sensitivity coefficient of the wetting front suction remained mostly between the aforementioned range (Figs. 14b and 15b).

Small values of the saturated hydraulic conductivity increased significantly the sensitivity coefficients of the streamflow volume and peak (Figs. 14c and 15c), whereas small values of the wetting front suction and the porosity did not imply an increase in the sensitivity coefficient greater than 0.40 for the streamflow volume and peak, excluding a sensitivity coefficient value of the wetting front suction for the streamflow peak (Fig. 14b).

The sensitivity coefficient of the streamflow volume varied more than that of the streamflow peak for the saturated hydraulic conductivity and porosity.

\subsection{Overall model parameter uncertainty analysis}

We selected the best simulated rainy season for the Middle Jaguaribe River (2005) and streamflow event for the Walnut Gulch Experimental Watershed (29 August 1972) and chose the most sensitive parameters found previously (Sect. 4.2) for both case studies, in order to carry out a combined ("overall") parameter uncertainty analysis based on the Monte Carlo approach. In this way, we ran the model 1000 times for the Jaguaribe River varying randomly the lateral and parallel saturated hydraulic conductivities from $1 \%$ to $199 \%$, and for the WGEW the saturated hydraulic conductivity and the wetting front suction from $1 \%$ to $199 \%$ and the porosity from $70 \%$ to $130 \%$. Then, we calculated the relative errors of the simulated streamflow volume and peak for the MJR and the WGEW. The relative errors are presented as box-plots in Fig. 16a-b: the relative errors of the simulations carried out for the WGEW (Fig. 16b) were much more variable than those for the MJR (Fig. 16a). The relative errors for the MJR were mostly in a very narrow range, where their inner quartile range (IQR) was practically zero, for both volume and peak. This rather stable behaviour (little overall parameter uncertainty) can be explained by the compensating effects of fluxes between/beneath the river and the adjacent aquifer and the associated levelling of hydraulic gradients. The fluxes are represented in the model by mathematically simple water budgeting in aquifer columns and the levelling effects are considered by the coupled processes, including backwater effects, see Sects. 2.4 and 2.5. Therefore, for the MJR rainy season 2005 , the relative error of the streamflow volume and peak was low, approximately $2 \%$ and $20 \%$, respectively, with $90 \%$ of certainty related to the model parameters.

The relative errors for the WGEW fell within much larger ranges, where their IQR was approximately $54 \%$ for the volume and $59 \%$ for the peak. This was a result of the 
07.28 .1972

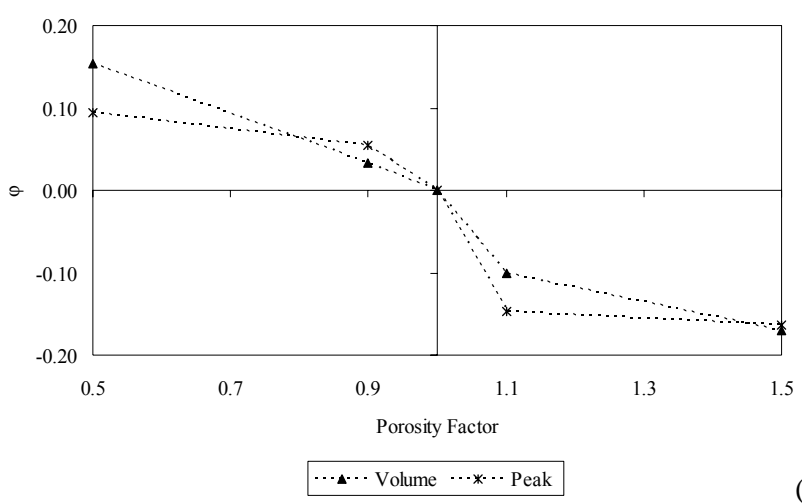

(a)

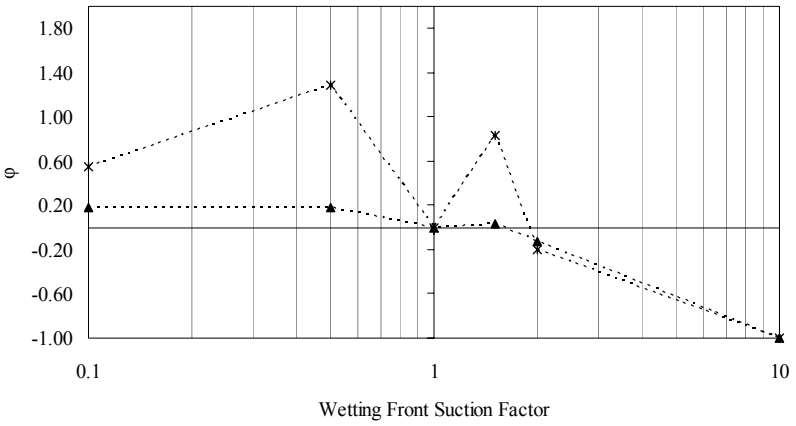

-... Volume $\cdots *$ - . Peak

07.28 .1972

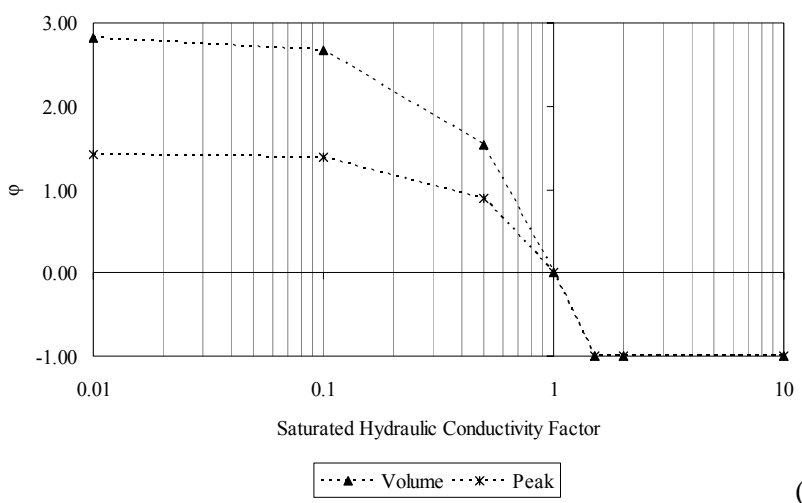

(c)

Fig. 14. (a) Sensitivity analysis of porosity, (b) sensitivity analysis of wetting front suction and (c) sensitivity analysis of saturated hydraulic conductivity, where $\phi$ is the sensitivity coefficient (Eq. 29) and $\mathrm{x}$-axis is the factor which was multiplied with the original values of the parameter (WGEW, 28 July 1972).

non-linearity involved in the unsaturated flow processes that prevail in disconnected dryland river systems. Such a nonlinear behaviour is represented, e.g. by the Green-and-Ampt equation (Sect. 2.2). In addition, a damping through feedback effects such as for the saturated fluxes does not exist.
08.02 .1968

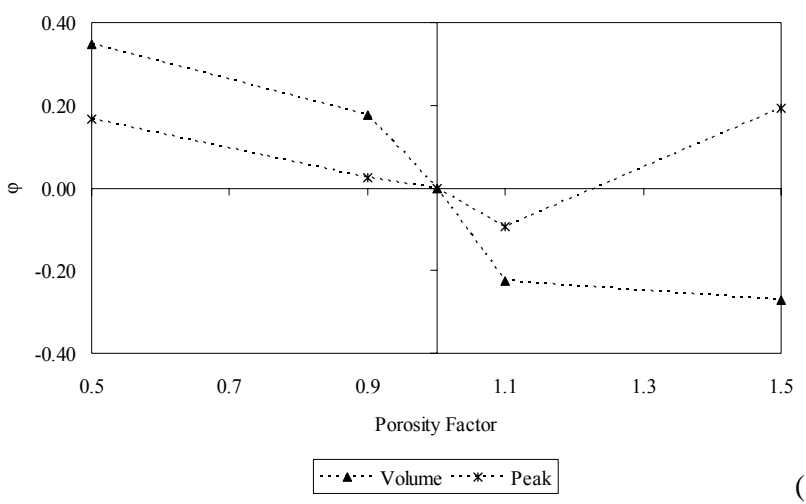

(a)

08.02 .1968

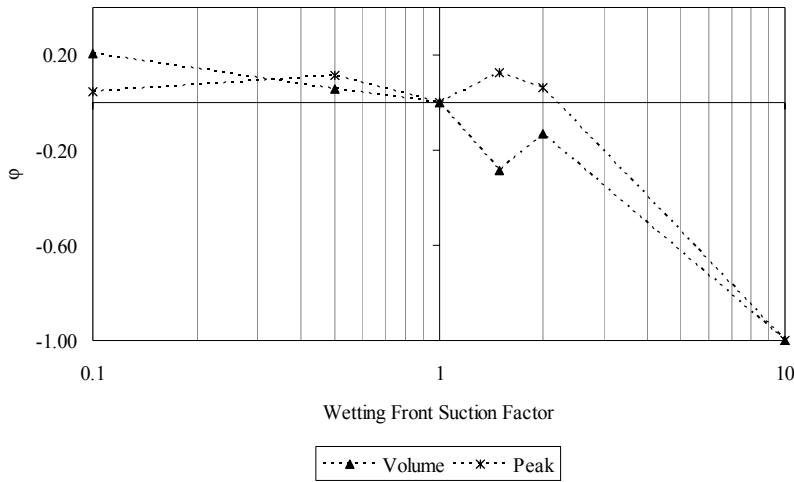

(b)

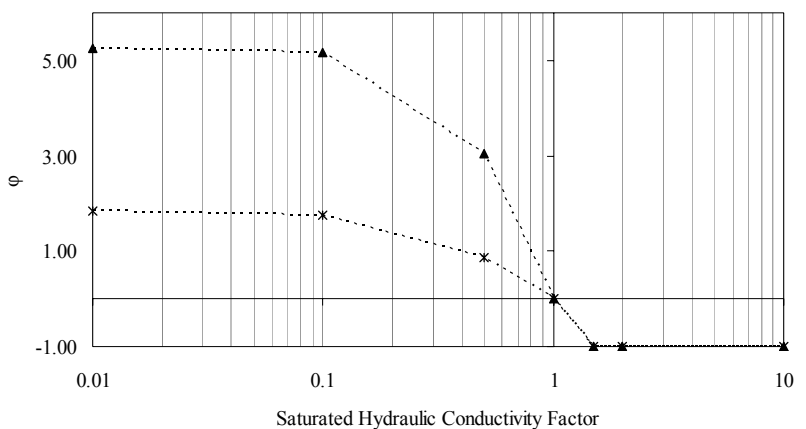

$\cdots$ - $\cdots$ Volume $\cdots * \cdots$ Peak

(c)

Fig. 15. (a) Sensitivity analysis of porosity, (b) sensitivity analysis of wetting front suction and (c) sensitivity analysis of saturated hydraulic conductivity, where $\phi$ is the sensitivity coefficient (Eq. 29) and $\mathrm{x}$-axis is the factor which was multiplied with the original values of the parameter (WGEW, 2 August 968).

Thus, for such conditions, the uncertainty is high, as demonstrated for the event on 29 August 1972, with a relative error $(\%)$ of the streamflow volume and peak between $[-91 ; 26]$ and $[-75 ; 46]$, respectively, with $80 \%$ of certainty related to the model parameters. 

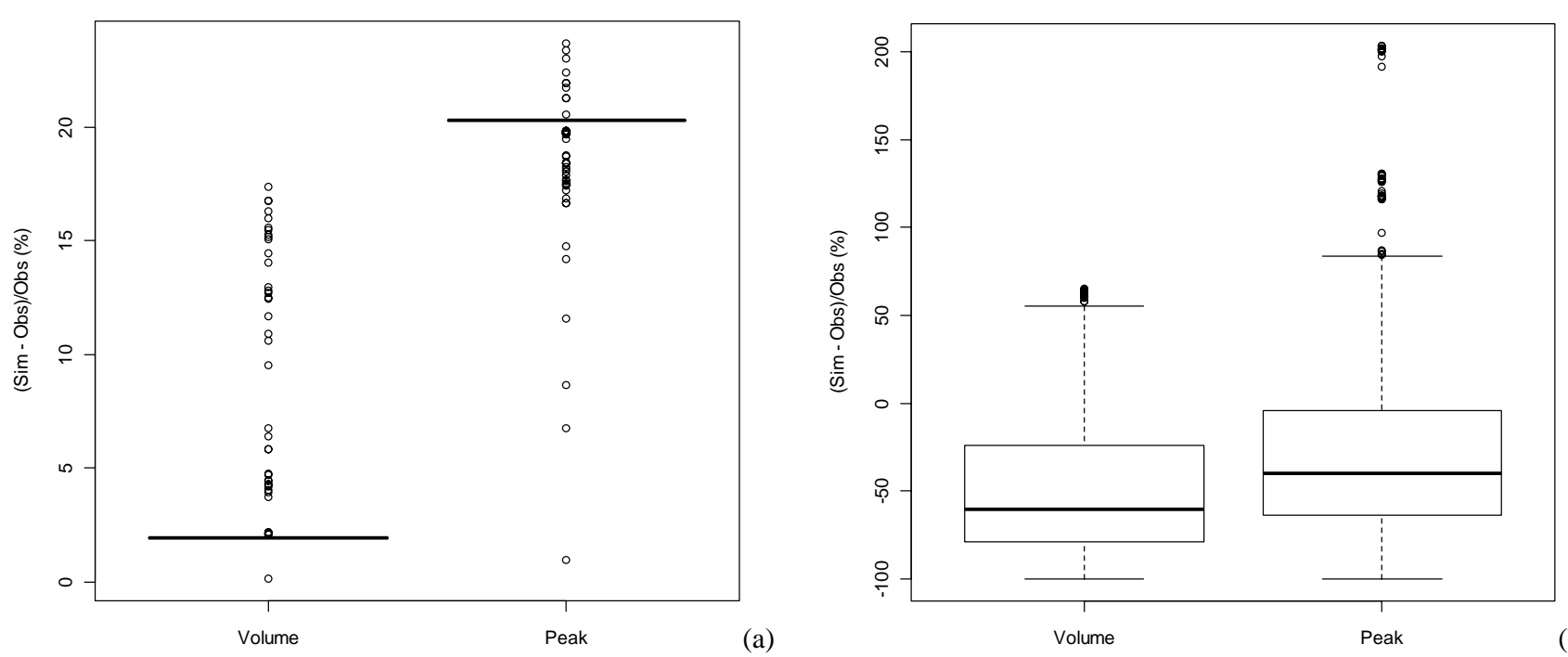

Fig. 16. (a) Relative errors of the simulated streamflow volume and peak in 2005 for the Jaguaribe River after 1000 simulations varying randomly the lateral and parallel saturated hydraulic conductivity from $1 \%$ to $199 \%$. (b) Relative errors of the simulated streamflow volume and peak on 29 August 1972 for the Walnut Gulch Experimental Watershed after 1000 simulations varying randomly the saturated hydraulic conductivity and the wetting front suction from $1 \%$ to $199 \%$ and the porosity from $70 \%$ to $130 \%$.

\section{Discussion}

The channel transmission losses model presented here has been developed for applications to different climate and hydro-geologic controls and scales of dryland rivers, covering a variety of hydrological processes relevant for inchannel transmission losses. In two case studies, it has predicted well the streamflow volume and peak for both a large losing/gaining, hydraulically connected river and a small losing, hydraulically disconnected stream. The model structure was chosen according to the hydrological perceptual models of the case studies, but no further parameter calibration procedure has been applied. That is why we consider the model to be well suited to the typical data scarce conditions in dryland areas. However, large uncertainties occur with reference to the timing of hydrographs, which is due to the simplified flood wave routing implemented, which is based only on the conservation of mass and the channel morphology. Therefore, the model can be used for water resources topics with a relatively long time scale, such as water resources planning and management purposes. However, it should not be applied to issues with short time scales, such as forecasting of flood wave timing as is necessary for flood warning.

The evaluation of the different model structures, which was conducted for the MJR case study, has shown that this procedure is promising for reducing structural model uncertainties and thus improving the capability for streamflow prediction in ungauged areas. This evaluation showed that adequate process representation improves the model reliability, e.g. in our case that both lateral (stream-)aquifer water fluxes and groundwater flow in the underlying alluvium parallel to the river course are necessary for physically-based prediction of streamflow and channel transmission losses, the former process being more relevant than the latter. The hydrological perceptual model of the MJR, which has been derived from field observations and data, and the modellingbased hypothesis-testing on the dominant processes complement each other and may provide a guide for further field campaigns and model expansions.

The analysis of the subsurface system simulations has shown that the reliable predictions of the surface flow volume and peak discharge is not necessarily sufficient to ensure a stable numerical solution of the subsurface processes in the unsaturated and saturated zones. Even if the influence of simulation time step and spatial discretization (e.g. the soil layer interval for the unsaturated flow) or of the boundary conditions (e.g. the groundwater flow of the farthest downstream aquifer unit) is analysed, a comprehensive evaluation of the model performance, comprising all processes of the model, is severely constrained by the particular data scarcity in dryland environments.

The sensitivity analysis showed that the model results were relatively little sensitive to the parameters related to the saturated fluxes (lateral stream-aquifer dynamics and groundwater flow parallel to the river course). This rather stable behaviour can be explained by the compensating effects of fluxes between the river and the adjacent groundwater and the associated levelling of hydraulic gradients. In other words, even if highly saturated hydraulic conductivities could "potentially" produce large fluxes between saturated model units, large fluxes did not happen because they were restricted by the actual hydraulic gradient between these model units, which are generally low, or may level out rather quickly. 
These parameters, which are related to the saturated part of the model, produced much smaller variation in the sensitivity coefficient than those which drive the unsaturated part of the channel transmission losses model (unsaturated stream infiltration and vertical soil water redistribution). This is explained by the aforementioned restriction of the subsurface hydraulic gradient, and on the other hand by a rather strong non-linear behaviour of the equations, which govern the unsaturated flow.

The overall parameter analysis (1000 simulation runs with different combinations of lateral and parallel saturated hydraulic conductivities) of the conditions in the Middle Jaguaribe River reach, where the saturated processes are dominant, yielded at most rather small relative errors $(2 \%$ for streamflow volume and $20 \%$ for peak). In contrast, the mean absolute error of the streamflow volume of the selected events was $41 \%, 10 \%$ and $4 \%$ for different model structure settings (Table 2). Therefore, at least for this case study, the uncertainties related to the model structure are considered to be larger than those related to the model parameters.

Rather large ranges for the simulated streamflow volume and peak based on 1000 simulations with different combinations of saturated hydraulic conductivity, wetting soil suction and soil porosity were found for the WGEW's stream, where unsaturated processes are dominant for runoff generation. Thus, applications of this model to real-world problems in data-scarce streams dominated by unsaturated processes may compromise inevitably high parameter uncertainties. Nevertheless, one has to acknowledge that this uncertainty is not a purely model uncertainty (or model artefact), rather that it is typical behaviour resulting from unstructured (or random) process dynamics for this kind of disconnected dryland rivers.

\section{Conclusions and outlook}

We developed a new process-oriented channel transmission losses model, which was designed to account for the surfacesubsurface water fluxes in data-scarce dryland environments. Channel transmission losses modelling is indispensable for simulation of arid and semi-arid watershed hydrology, as long as the underlying aquifer system has not been fully saturated, as is expected to occur in ephemeral streams and in intermittent rivers in the dry seasons and at the beginning and in the middle of the rainy seasons (Renard, 1970; Costa et al., 2012). Moreover, in (sub-)humid rivers vertical and lateral groundwater recharge can occur from winter to spring, when the surface water stages are higher than the groundwater table (see e.g. Krause and Bronstert, 2007). This recharge after drought periods or during extensive groundwater pumping may be intensified and resemble channel transmission losses of dryland rivers.
The main findings of our work can be described as follows:

1. A mathematically flexible and hydrologically complex modelling of the channel transmission losses can represent well the most relevant hydrological processes for streamflow prediction in dryland rivers throughout different scales and controls.

2. A test of different model structures enables the comparative application of the channel transmission losses model to a poorly gauged river and yields information on the relevance of different sub-systems and processes.

3. High nonlinear approaches, which were used for the unsaturated zone processes, are much more sensitive to parameter variability than those of mathematically simple, but hydrologically two-way-coupled, approaches, which were used for the saturated zone.

4. Uncertainties arising from the model structure were more relevant than those related to the parameter variability of the saturated part of the model in the Middle Jaguaribe River application.

5. The scarcity of data in dryland environments and the process complexity involved in the unsaturated flow lead to the view that disconnected systems (e.g. the WEGW's) controlled by the unsaturated zone generally compromise model uncertainties much more than do connected systems (e.g. the MJR) that are driven by the saturated flow. Therefore, the degree of aridity of a dryland river may be an indicator of its model uncertainty/predictability.

The model might be further tested and possibly improved - particularly its subsurface part - based on comparison with additional groundwater observational data. This may improve the reliability of its internal processes representation (e.g. unsaturated flow and groundwater flow) and subsequently its applicability for ungauged situations (based on Andréassian et al., 2007, 2009, 2010; Bronstert, 2004). In this respect, we have been monitoring groundwater level close to the outlet of the studied reach of the Middle Jaguaribe River, whose first results were presented in Costa et al. (2012). Moreover, an obvious aim is the integration of this model with a dryland hydrological catchment model for semi-arid hydrology (see e.g. Güntner and Bronstert, 2004; Güntner et al., 2004).

The increase in data availability, in particular from the subsurface structures, may allow a finer spatial discretization of model units, i.e. moving from the actual semi-distributed to a distributed hydrological concept and/or introducing additional processes. Such a strategy, for example, was followed over the past decades for the hydrological modelling of the Okavango Delta System in Botswana, where surfacesubsurface fluxes were simulated initially by conceptual models and then later on by fully-distributed ones (e.g. Bauer et al., 2006; Milzow et al., 2009). 
Acknowledgements. The first author thanks the Brazilian National Council for Scientific and Technological Development (CNPq) for the PhD-scholarship. We thank David Goodrich for his comments on the literature review section and the section applicable to Walnut Gulch Research Watershed. We thank the Brazilian Geological Service (CPRM), the Brazilian Water Agency (ANA) and the Meteorological and Water Resources Foundation of the State of Ceará (FUNCEME). Datasets were also provided by the USDA-ARS Southwest Watershed Research Center. Funding for these datasets was provided by the United States Department of Agriculture, Agricultural Research Service. We are also grateful to the two reviewers for their comments and suggestions, which improved this paper significantly.

Edited by: M. Werner

\section{References}

Abdulrazzak, M. J. and Morel-Seytoux, H.: Recharge from an ephemeral stream following wetting front arrival to water table, Water Resour. Res., 19, 194-200, 1983.

Al-Qurashi, A., McIntyre, N., Wheater, H., and Unkrich, C.: Application of the Kineros2 rainfall-runoff model to an arid catchment in Oman, J. Hydrol., 355, 91-105, doi:10.1016/j.jhydrol.2008.03.022, 2008.

Andréassian, V., Lerat, J., Loumagne, C., Mathevet, T., Michel, C., Oudin, L., and Perrin, C.: What is really underminig hydrologic science today?, Hydrol. Process., 21, 2819-2822, doi:10.1002/hyp.6854, 2007.

Andréassian, V., Perrin, C., Berthet, L., Le Moine, N., Lerat, J., Loumagne, C., Oudin, L., Mathevet, T., Ramos, M.-H., and Valéry, A.: HESS Opinions "Crash tests for a standardized evaluation of hydrological models", Hydrol. Earth Syst. Sci., 13, 1757-1764, doi:10.5194/hess-13-1757-2009, 2009.

Andréassian, V., Perrin, C., Parent, E., and Bárdossy, A.: The court of miracles of hydrology: can failure stories contribute to hydrological science?, Hydrol. Sci. J., 55, 849-856, 2010.

Arnold, J. G. and Williams, J. R.: SWRRB - A watershed scale model for soil and water resources management, in: Computer Models of Watershed Hydrology, edited by: Singh, V. P., Water Resources Publications, Colorado, USA, 847-908, 1995.

Bauer, P., Gumbricht, T., and Kinzelbach, W.: A regional coupled surface water/groundwater model of the Okavango Delta, Botswana, Water Resour. Res., 42, W04403, doi:10.1029/2005WR004234, 2006.

Beven, K. J.: Runoff generation in semi-arid areas, in: Dryland Rivers: Hydrology and Geomorphology of Semi-Arid Channels, edited by: Bull, L. J. and Kirkby, M. J., John Wiley \& Sons, Chichester, England, 2002.

Blasch, K., Ferré, T. P. A., Hoffman, J., Pool, D., Bailey, M., and Cordova, J.: Process controlling recharge beneath ephemeral streams in Southern Arizona, in: Groundwater Recharge in a Desert Environment: The Southwestern United States, Water Science and Application 9, edited by: Hogan, J. F., Phillips, F. M., and Scanlon, B. R., American Geophysical Union, Washington, 2004.

Bracken, L. and Croke, J.: The concept of hydrological connectivity and its contribution to understanding runoff-dominated geomorphic systems, Hydrol. Process., 21, 1749-1763, 2007.
Bronstert, A.: Rainfall-runoff modelling for assessing impacts of climate and land-use change, Hydrol. Process., 18, 567-570, doi:10.1002/hyp.5500, 2004.

Bronstert, A., Carrera, J., Kabat, P., and Lütkemeier, S.: Coupled Models for the Hydrological Cycle: Integrating Atmosphere, Biosphere and Pedosphere, Springer Verlag, Berlin, 2005.

Brunner, P., Simmons, C. T., Cook, P. G., and Therrien, R.: Modeling surface water-groundwater interaction with MODFLOW: some considerations, Ground Water, 48, 174-180, doi:10.1111/j.1745-6584.2009.00644.x, 2010.

Bull, L. J. and Kirkby, M. J.: Dryland river characteristics and concepts, in: Dryland Rivers: Hydrology and Geomorphology of Semi-Arid Channels, edited by: Bull, L. J. and Kirkby, M. J., John Wiley \& Sons, Chichester, England, 2002.

Buytaert, W. and Beven, K.: Models as multiple working hypotheses: hydrological simulation of tropical alpine wetlands, Hydrol. Process., 25, 1784-1799, doi:10.1002/hyp.7936, 2011.

Carneiro, F. B.: Withdrawal situation for water supply system of Iguatu city - Ceará, Fundação Nacional de Saúde, Fortaleza, Ceará, Brasil, 1993.

Clark, M. P., McMillan, H. K., Collins, D. B. G., Kavetski, D., and Woods, R. A.: Hydrological field data from a modeller's perspective: Part 2: process-based evaluation of model hypotheses, Hydrol. Process., 25, 523-543, doi:10.1002/hyp.7902, 2011.

Chow, V. T., Maidment, D. R., and Mays, L. W.: Applied Hydrology, McGraw-Hill, Singapure, 1988.

Chu, X. and Mariño, M. A.: Determination of ponding condition and infiltration into layered soils under unsteady rainfall, J. Hydrol., 313, 195-207, 2005.

Costa, A.C., Foerster, S., De Araújo, J. C., and Bronstert, A.: Analysis of channel transmission losses in a dryland river reach in northeastern Brazil using streamflow series, groundwater level series and multi-temporal satellite data, Hydrol. Process., doi:10.1002/hyp.9243, in press, 2012.

Costelloe, J., Grayson, R., and McMahon, T.: Modelling streamflow in a large anastosing river of the arid zone, Diamantina River, Australia, J. Hydrol., 323, 138-153, 2006.

Dagès, C., Voltz, J. G., Lacas, O., Huttel, O., Negro, S., and Louchart, X.: An experimental study of water table recharge by seepage losses from a ditch with intermittent flow, Hydrol. Process., 22, 3555-3563, doi:10.1002/hyp.6958, 2008.

Dahan, O., Shani, Y., Enzel, Y., Yechieli, Y., and Yakirevich, A.: Direct measurements of floodwater infiltration into shallow alluvial aquifers, J. Hydrol., 344, 157-170, doi:10.1016/j.jhydrol.2007.06.033, 2007.

Dahan, O., Tatarsky, B., Enzel, Y., Kulls, C., Seely, M., and Benito, G.: Dynamics of flood water infiltration and ground water recharge in hyperarid desert, Ground Water, 46, 450-461, doi:10.1111/j.1745-6584.2007.00414.x, 2008.

Dingman, L. S.: Physical Hydrology, 2nd Edn., Prentice Hall, Upper Saddle River, USA, 2002.

Dunkerley, D. and Brown, K.: Flow behaviour, suspended sediment transport and transmission losses in a small (sub-bank-full) flow event in an Australian desert stream, Hydrol. Process., 13, 1577-1588, 1999.

El-Hames, A. S. and Richards, S. K.: An integrated, physically based model for arid region flash flood prediction capable of simulating dynamic transmission loss, Hydrol. Process., 12, 12191233, 1998. 
Emmerich, W. E.: Soil Survey of Walnut Gulch Experimental Watershed, Arizona, Special Report, National Cooperative Soil Survey, USDA-ARS, Tucson, USA, 2008.

Engeler, I., Hendricks-Franssen, H. J., Müller, R., and Stauffer, F.: The importance of coupled modelling of variably saturated groundwater flow-heat transport for assessing river-aquifer interactions, J. Hydrol., 397, 295-305, 2011.

Fread, D.L.: Flow routing, in: Handbook of Hydrology, edited by: Maidment, D. R., McGraw-Hill Inc., New York, USA, 1993.

Freyberg, D. L.: Modeling the effects of a time-dependent wetted perimeter on infiltration from ephemeral channels, Water Resour. Res., 19, 559-566, 1983.

Freyberg, D. L., Reeder, J. W., Franzini, J. B., and Remson, I.: Application of the Green-Ampt model to infiltration under timedependent surface water depths, Water Resour. Res., 16, 517$528,1980$.

Gheith, H. and Sultan, M.: Construction of a hydrology model for estimating wadi runoff and groundwater recharge in the Eastern Desert, Egypt, J. Hydrol., 263, 36-55, 2002.

Goodrich, D. C., Williams, D. G., Unkrich, C. L., Hogan, J. F., Scott, R. L., Hultine, K. R., Pool, D., Coes, A. L., and Miller, S.: Comparison of methods to estimate ephemeral channel recharge, Walnut Gulch, San Pedro River, in: Groundwater Recharge in a Desert Environment: The Southwestern United States, Water Science and Application 9, edited by: Hogan, J. F., Phillips, F. M., and Scanlon, B. R., American Geophysical Union, Washington, 294 pp., 2004.

Graeff, T., Zehe, E., Reusser, D., Lück, E., Schröder, B., Wenk, G., John, H., and Bronstert, A.: Process identification through rejection of model structures in a mid-mountainous rural catchment: observations of rainfall-runoff response, geophysical conditions and model inter-comparison, Hydrol. Process., 23, 702$718,2009$.

Güntner, A. and Bronstert, A.: Representation of landscape variability and lateral redistribution processes for large-scale hydrological modelling in semi-arid areas, J. Hydrol., 297, 136-161, 2004.

Güntner, A., Krol, M. S., De Araújo, J., and Bronstert, A.: Simple water balance modelling of surface reservoir systems in a large data-scarce semiarid region, Hydrolog. Sci. J., 5, 145-164, 2004.

Hameed, T., Mariño, M. A., and Cheema, M. N.: Time series modelling of channel transmission losses, Agr. Water Manage., 29, 283-298, 1996.

Hillel, D.: Fundamentals of Soil Physics, Academic Press, San Diego, California, 413 pp., 1980.

Hughes, D. A.: Modelling semi-arid and arid hydrology and water resources: the southern Africa experience, in: Hydrological Modelling in Arid and Semi-Arid Areas, edited by: Wheater, H., Sorooshian, S., and Sharma, K. D., Cambridge Press, New York, USA, 2008.

IBGE - Brazilian Institute of Geography and Statistics: Hydrogeological Map of Iguatu Micro-region (SB24YB), http://www. ibge.gov.br/home/geociencias/default_prod.shtm\#HIDROGEO (last access: 24 April 2008) 2003.

Ivkovic, K. M.: A top-down approach to characterise aquifer-river interaction processes, J. Hydrol., 365, 145-155, 2009.

Knighton, A. D. and Nanson, G. C.: Flow transmission along an arid zone anastomosing river, Copper Creek, Australia, Hydrol. Process., 8, 137-153, 1994.
Konrad, C. P.: Location and timing of river-aquifer exchanges in six tributaries to the Columbia River in the Pacific Northwest of the United States, J. Hydrol., 329, 444-470, 2006.

Krause, S. and Bronstert, A.: The impact of groundwater-surface water interactions on the water balance of a mesoscale lowland river catchment in northeastern Germany, Hydrol. Process., 21, 169-184, doi:10.1002/hyp.6182, 2007.

Lane, L. J.: Transmission losses, in: National Engineering Handbook Section NEH-4: Hydrology, chap. 19, edited by: Soil Conserv. Serv., US Dep. of Agric., Washington, D.C., 1-21, 1983.

Lange, J., Leibundgut, C., Greenbaum, N., and Schick, A. P.: A noncalibrated rainfall-runoff model for large, arid catchments, Water Resour. Res., 35, 2161-2173, 1999.

Lange, J.: Dynamics of transmission losses in a large arid stream channel, J. Hydrol., 306, 112-126, 2005.

Lange, L., Leibundgut, Ch., Schwartz, U., Grodek, T., Lekach, J., and Schick, A. P.: Using artificial tracers to study water losses of ephemeral floods in small arid streams, IAHS Publ., 247, 31-40, 1998.

Li, H., Sivapalan, M., and Tian, F.: Comparative diagnostic analysis of runoff generation processes in Oklahoma DMIP2 basins: The Blue River and Illinois River, J. Hydrol., 418-419, 90-109, doi:10.1016/j.jhydrol.2010.08.005, 2010.

McMillian, H. K., Clark, M. P., Bowden, W. B., Duncan, M., and Woods, R. A.: Hydrological field data from a modeller's perspective: Part 1. Diagnostic tests for model structure, Hydrol. Process., 25, 511-522, doi:10.1002/hyp.7841, 2011.

Milewski, A., Sultan, M., Yan, E., Becker, R., Abdeldayem, A., Soliman, F., and Gelil, K. A.: A remote sensing solution for estimating runoff and recharge in arid environments, J. Hydrol., 373, 1-14, doi:10.1016/j.jhydrol.2009.04.2002, 2009.

Miller, S. N., Guertin, D. P., and Goodrich, D. C.: Deriving stream channel morphology using GIS-based watershed analysis, in: GIS for Water Resources and Watershed Management, edited by: Lyon, J. G., Taylor and Francis, New York, 2003.

Milzow, C., Kgotlhang, L., Bauer-Gottwein, P., Meier, P., and Kinzelbach, W.: Regional review: the hydrology of the Okavango Delta, Botswana - processes, data and modeling, Hydrogeol. J., 17, 1297-1328, 2009.

Morin, E., Grodek, T., Dahan, O., Benito, G., Kulls, C., Jacoby, Y., Van Langenhove, G., Seely, M., and Enzel, Y.: Flood routing and alluvial aquifer recharge along the ephemeral arid Kuiseb River, Nambia, J. Hydrol., 368, 262-275, 2009.

Mudd, S. M.: Investigation of the hydrodynamics of flash floods in ephemeral channels: scaling analysis and simulation using a shock-capturing flow model incorporating the effects of transmission losses, J. Hydrol., 324, 65-79, 2006.

Niu, G.-Y., Yang, Z.-L., Dickinson, R. E., Gulden, L. E., and $\mathrm{Su}$, H.: Development of a simple groundwater model for use in climate models and evaluation with Gravity Recovery and Climate Experiment data, J. Geophys. Res., 112, D07103, doi:10.1029/2006JD007522, 2007.

Osterkamp, W. R.: Geology, soils and geomorphology of the Walnut Gulch Experimental Watershed, Tombstone, Arizona, J. Arizona-Nevada Acad. Sci., 40, 136-154, 2008.

Parissopoulos, G. A. and Wheater, H. S.: Experimental and numerical infiltration studies in a wadi stream bed, Hydrolog. Sci. J., 37, 27-37, 1992. 
Rawls, W. J., Ahuja, L. R., Brakensiek, D. L., and Shirmohammadi, A.: Infiltration and soil water movement, in: Handbook of Hydrology, edited by: Maidment, D. R., McGraw-Hill Inc., USA, 1993.

Renard, K. G.: The hydrology of semiarid rangeland watersheds, Rep. ARS-41-162, Agric. Res. Serv., US Dep. of Agric., Washington, D.C., 1970.

Renard, K. G., Nichols, M. H., Woolhiser, D. A., and Osborn, H. B.: A brief background on the U.S. Department of Agriculture Agricultural Research Service Walnut Gulch Experimental Watershed, Water Resour. Res., 44, W05S02, doi:10.1029/2006WR005691, 2008.

Rushton, K. R. and Tomlinson, L. M.: Possible mechanisms for leakage between aquifers and rivers, J. Hydrol., 40, 49-65, 1979.

Savenije, H. H. G.: HESS Opinions "The art of hydrology"*, Hydrol. Earth Syst. Sci., 13, 157-161, doi:10.5194/hess-13-1572009, 2009.

Semmens, D. J., Goodrich, D. C., Unkrich, C. L., Smith, R. E., Woolhiser, D. A., and Miller, S. N.: KINEROS2 and the AGWA modeling framework, in: Hydrological Modelling in Arid and Semi-Arid Areas, edited by: Wheater, H., Sorooshian, S., and Sharma, K. D., Cambridge Press, New York, 2008.

Shannon, J., Richardson, R., and Thornes, J.: Modelling Eventbased Fluxes in Ephemeral Streams, in: Dryland Rivers: Hydrology and Geomorphology of Semi-Arid Channels, edited by: Bull, L. J. and Kirkby, M. J., John Wiley \& Sons, Chichester, England, 2002.

Sharma, K. D. and Murthy, J. S. R.: Estimating transmission losses in an arid region - a realistic approach, J. Arid Environ., 27, 107113,1994

Sharma, K. D., Murthy, J. S. R., and Dhir, R. P.: Streamflow routing in the Indian Arid zone, Hydrol. Process., 8, 27-43, 1994.

Smith, R. E., Goodrich, D. C., Woolhiser, D. A., and Unkrich, C. L.: KINEROS - A kinematic runoff and erosion model, in: Computer Models of Watershed Hydrology, Water Resources Pub., edited by: Singh, V. J., Highlands Ranch, Colorado, 1995.
Sophocleous, M.: Interactions between groundwater and surface water: the state of the science, Hydrogeol. J., 10, 52-67, doi:10.1007/s10040-001-0170-8, 2002.

Spangler, D. P.: A geophysical study of the hydrology of the Walnut Gulch Experimental Watershed, Tombstone, Arizona, PhD Dissertation, Dept. of Geology, Univ. of Arizona, Tucson, 103 pp., 1969.

Stone, J. J., Nichols, M. H., Goodrich, D. C., and Buono, J.: Long-term runoff database, Walnut Gulch Experimental Watershed, Arizona, United States, Water Resour. Res., 44, W05S05, doi:10.1029/2006WR005733, 2008.

Van Dam, J. C. and Feddes, R. A.: Numerical simulation of infiltration, evaporation and shallow groundwater levels with the Richards equation, J. Hydrol., 233, 72-85, 2000.

Van Oel, P., Krol, M., Hoeckstra, A., and de Araújo, J. C.: The impact of upstream water abstractions on reservoir yield: the case of the Orós Reservoir in Brazil, Hydrol. Sci. J., 53, 857-867, 2008.

Werner, P. C. and Gerstengarbe, F-W.: The climate of Piauí and Ceará, in: Global Change and Regional Impacts, edited by: Gaiser, T., Krol, M., Frischkorn, H., and De Araújo, J. C., Springer Verlag, Berlin, 81-86, 2003.

Wheater, H.: Modelling hydrological processes in arid and semiarid areas: an introduction, in: Hydrological Modelling in Arid and Semi-Arid Areas, edited by: Wheater, H., Sorooshian, S., and Sharma, K. D., Cambridge Press, New York, 2008.

Xavier, T. M. B. S.: Time for Rainfall: Climatological and Forecasting Studies for Ceará and Northeast, ABC Editora: Fortaleza, Ceará, Brazil, 2001.

Xie, Z. and Yuan, X.: Prediction of water table under stream-aquifer interactions over an arid region, Hydrol. Process., 24, 160-169, doi:10.1002/hyp.7434, 2010. 